\title{
MANEUVERING IN POOR VISIBILITY: HOW FIRMS PLAY THE ECOSYSTEM GAME WHEN UNCERTAINTY IS HIGH
}

\author{
BRICE DATTÉE \\ Emlyon Business School \\ OLIVER ALEXY \\ Technische Universität München \\ ERKKO AUTIO \\ Imperial College London \\ and \\ Tilburg University School of Economics and Management
}

\begin{abstract}
Innovation ecosystems are increasingly regarded as important vehicles to create and capture value from complex value propositions. While current literature assumes these value propositions can be known ex ante and an appropriate ecosystem design derived from them, we focus on generative technological innovations that enable an unbounded range of potential value propositions, hence offering no clear guidance to firms. To illustrate our arguments, we inductively study two organizations, each attempting to create two novel ecosystems around new technological enablers deep in their industry architecture. We highlight how ecosystem creation in such conditions is a systemic process driven by coupled feedback loops, which organizations must try to control dynamically: firms first make the switch to creating the ecosystem, following an external pull to narrow down the range of potential applications; then need to learn to keep up with ecosystem dynamics by roadmapping and preempting, while simultaneously enacting resonance. Dynamic control further entails counteracting the drifting away of the nascent ecosystem from the firm's idea of future value creation and the sliding of its intended control points for value capture. Our findings shed new light on strategy and control in emerging ecosystems, and provide guidance to managers on playing the ecosystem game.
\end{abstract}

Firms increasingly form "innovation ecosystems" to implement complex value propositions (e.g., Adner, 2012; Kapoor \& Lee, 2013; Nambisan \& Baron, 2013; van der Borgh, Cloodt, \& Romme, 2012; Williamson \& De Meyer, 2012). Defined as "the collaborative arrangements through which firms combine their individual offerings into a

All authors would like to acknowledge funding from the Engineering and Physical Sciences Research Council (GR/R95371/01). We would further like to thank Carliss Baldwin, Ammon Salter, and Victor Seidel, as well as seminar and conference participants at Copenhagen Business School, Emlyon Business School, TU Eindhoven, the University of Cologne, and the Academy of Management-Technology and Innovation Management 2016 Workshop for their helpful comments. We also appreciate the feedback on earlier versions of this paper from participants at the DRUID and Academy of Management conferences. All remaining errors are of course our own. coherent, customer-facing solution" (Adner, 2006: 98), at the core of an innovation ecosystem one often finds a technology platform: a set of shared assets, standards, and interfaces that underpins an activity system surrounding it (Gawer, 2014; Thomas, Autio, \& Gann, 2014). Such platforms typically reside upon a layered digital infrastructure, where lower-level layers (e.g., physical components, transmission layer) enable and support functionalities at higher, user-facing layers (e.g., operating systems layer, application layer) (Tilson, Lyytinen, \& Sørensen, 2010; Yoo, Henfridsson, \& Lyytinen, 2010). To create value, ecosystems hence depend on complementary inputs made by loosely interconnected, yet independent stakeholders from varying levels of (technological) distance from the end consumer (Adner, 2006; Pagani, 2013).

How do such ecosystems come into being? While there has been increasing research on the distinct governance and orchestration challenges presented 
by established innovation ecosystems (e.g., Dhanaraj \& Parkhe, 2006; Nambisan \& Sawhney, 2011; Wareham, Fox, \& Cano Giner, 2014), much less work has addressed how prospective ecosystem stakeholders commit resources toward a de novo ecosystem creation effort and how they evolve a shared structure of interactions (Autio \& Thomas, 2013; Hannah \& Eisenhardt, 2015). Yet, committing to a de novo ecosystem creation effort is not a simple endeavor, as ecosystem value propositions typically depend on the concurrent availability of complementary inputs from varied, independent stakeholders (Ceccagnoli, Forman, Huang, \& Wu, 2012; Davis, 2013). This mutual dependency in value creation creates a "chicken and egg" problem: if the platform or its complements are of little value in isolation, how does one persuade someone to commit first, and evolve a collective framework of participation?

The standard response to this dilemma is that the ecosystem champion, or "keystone" (Iansiti \& Levien, 2004), should come up with a compelling "blueprint" for the future ecosystem; one vision that clearly defines the ecosystem value proposition (i.e., what value is created, how, and for whom) and associated structures of governance and interaction (i.e., who does what, who controls what, and how everyone will benefit) (Adner, 2006, 2012; Edelman, 2015; Eisenmann, 2008; Iansiti \& Levien, 2004; Williamson \& De Meyer, 2012). A compelling vision, hence, reduces uncertainty, facilitates coordination, and enables the focal firm to paint the future ecosystem as an impending reality, prompting potential stakeholders to join early for fear of "missing the train" (Ozcan \& Eisenhardt, 2009; Santos \& Eisenhardt, 2009).

However, such tactics rely on the common and fundamental assumption that it is possible to envision, ex ante, one compelling ecosystem blueprint that is tangible enough to reduce uncertainty, so that appropriate action for the present can be inferred (almost) by logic alone. Such envisioning is easier in situations where user needs are relatively well known and the customer-facing value proposition can be tangibly imagined. For example, Apple was able to tangibly describe its vision for the future iTunes-, iPod-, and iPhone-centric music ecosystem, allowing record labels to comprehend how the ecosystem would work and anticipate their role in itincluding how they would make money from it (Eaton, Elaluf-Calderwood, Sørensen, \& Yoo, 2011; Ingraham, 2013).

Such envisioning, however, is not always possible (Anderson, 1999; Dougherty \& Dunne, 2011; Dunne \& Dougherty, 2016), particularly not when it is built on generative technologies-technologies that have the potential to produce unprompted change and to create a breathtaking variety of potential future applications (Gruber, MacMillan, \& Thompson, 2008; Zittrain, 2006). For example, attempts to introduce new technologies at lower layers of the digital infrastructure (say, new chip standards to enable near-field communications for "Internet of Things" applications) typically tend to enable such a large number of potential user-facing applications at upper layers that this can easily overwhelm prospective stakeholders. In turn, this may undermine the ecosystem champion's efforts to come up with a single vision that is compelling enough to crowd out alternative visions so as to align required stakeholders around it, while positioning itself to occupy the "bottleneck" positions within the ecosystem to appropriate a disproportionate share of the collectively created value (Baldwin, 2015; Hannah \& Eisenhardt, 2015; Jacobides \& Tae, 2015).

These considerations highlight the question we address in this paper: how does an ecosystem champion compel others to commit to a de novo ecosystem creation effort in a situation where uncertainty is so high that: (1) it is not possible to create a meaningful vision to simply enlist prospective stakeholders, and (2) ecosystem champions themselves do not have good enough visibility to inform them on how to position themselves adequately for eventual value appropriation once an ecosystem, whatever it may look like, is in place?

We chose an embedded multiple-case design based on literal replication (Yin, 2014) to tackle this question. We conducted in-depth qualitative process research (Gioia, Corley, \& Hamilton, 2013) with two multinational technology firms, for each of which we studied two attempts to imagine novel and complex value propositions and create the innovation ecosystems required to deliver and exploit them. We draw on a series of primary interviews and extensive secondary data as a baseline for these four case studies and take several measures to corroborate our theorizing.

Our findings support three notable contributions to the literature on innovation strategy and strategic entrepreneurship. First, we extend received wisdom on the effective design of innovation ecosystems (e.g., Adner, 2012; Gawer \& Cusumano, 2002; Iansiti \& Levien, 2004) to contexts in which these cannot be reliably planned, as no clear value proposition to orchestrate the ecosystem exists ex ante. We show how, in such cases, ecosystem creation becomes a process of collective discovery orchestrated by the focal firm, which tries to delay its resource commitments for as 
long as possible to prevent betting on the wrong horse. Second, in order to understand how firms can successfully navigate this context, we emphasize a systems (dynamics) perspective on ecosystems (see, e.g., Azoulay, Repenning, \& Zuckerman, 2010; Morecroft, 2007; Repenning \& Sterman, 2002; Sterman, 2000). In doing so, we show that firms that want to win at the ecosystem game need to establish dynamic control over the creation process. Specifically, they need to draw on influencing, monitoring, and updating strategies to ensure that the emerging value proposition will evolve in such a way that control points through which the firm hopes to capture some of the created value can actually ever apply. Finally, we highlight how our insights may hold the potential to provide a fresh view toward combining more goal-oriented (Gruber et al., 2008, 2013; McGrath \& MacMillan, 2000) and more processoriented (Baker \& Nelson, 2005; Sarasvathy, 2001; Sarasvathy, Dew, Read, \& Wiltbank, 2008) perspectives of entrepreneurship.

\section{NEW VALUE PROPOSITIONS AND INNOVATION ECOSYSTEMS}

Innovation ecosystems have become a prominent topic in the strategy and innovation literature (Adner, Oxley, \& Silverman, 2013). First, for increasingly complex products and services that require the collaboration of multiple parties, we need new perspectives that allow us to understand how to create (more) value to existing customers or create entirely new value propositions altogether (Adner \& Kapoor, 2010; Chesbrough, 2003; Lusch \& Nambisan, 2015; Tilson et al., 2010). Ecosystems are of practical as well as theoretical interest in this context, given how this perspective may allow us to think afresh about how value is created-namely by consumers choosing certain bundles around a key value proposition in order to satisfy their idiosyncratic needs (Priem, 2007). In turn, given their "mix-and-match" nature, moving to an ecosystem perspective may fundamentally broaden the heterogeneity of customers a company may address and, hence, the value the firm may create. Second, ecosystems hold considerable promise for improved value capture. Driven by direct and indirect network externalities (e.g., Boudreau, 2010), ecosystems may evolve-or be steered-in a way that they may generate substantial abnormal returns to the firms in control of them (Adner, 2006, 2012; Iansiti \& Levien, 2004; Moore, 1996)—with Apple, Google, Intel, or Microsoft as frequently named successful examples.
Trying to explicate these benefits and how to reach them has been the focus of a growing body of academic as well as practitioner-oriented work. We identified $^{1}$ a significant number of studies discussing the design and governance of innovation ecosystems, industry platforms, or multisided markets in specific industries characterized by disintegrated value chains and highly heterogeneous demands (for recent reviews, see also Autio \& Thomas, 2013; Gawer, 2014; Narayanan \& Chen, 2012; Thomas et al., 2014).

However, we also found that those demands are almost exclusively assumed to be known ex ante, with all ecosystem stakeholders being aware of them and each other (and who would be the keystone, complementors, or suppliers). Hence, existing literature seems to have posited that the ultimate value proposition of the to-be-created innovation ecosystem can be constructed following an almost linear plan. The focus is thus put on questions of behavioral maneuvering-which is deduced from the clearly envisioned future-to ensure this value proposition will come true and that the focal firm becomes instrumental in this process (e.g., Adner \& Kapoor, 2010; Ansari, Garud, \& Kumaraswamy, 2015; Kapoor \& Furr, 2015; McIntyre \& Subramaniam, 2009; Wareham et al., 2014). ${ }^{2}$

More specifically, we found that this assumption may take several forms. A large focus of the literature rests on customer-facing firms in existing businessto-consumer (B2C) markets. Of course, these firms have access to consumer needs and may derive suitable value propositions as well as strategies for implementing them. However, when a multilayered industry is already established, even firms without such direct customer access, such as Microsoft and

\footnotetext{
${ }^{1}$ Across all major academic and practitioner-oriented journals, we systematically searched for the words "platform," "standard," or "ecosystem." When the title or abstract of a paper appeared to fit our inquiry, we read the entire paper, paying particular attention to whether a specific empirical context had been predefined for the study, or whether assumptions existed about how value propositions could be generated. We proceeded analogously for books.

${ }^{2}$ For example, Ansari et al. (2015: 1830) explained how TiVo overcame coopetitive tensions to "graft its innovation into an existing ecosystem." While the outcomes were uncertain, the nature of the value proposition and the set of actors were determined. As Zittrain (2006) argued, TiVo represents a class of appliances that exploit the generativity of the deeper layers of the Open Systems Interconnection (OSI) hierarchy but which are not generative in themselves.
} 
Intel, may know what downstream customers appreciate (e.g., Adner, 2012; Casadesus-Masanell \& Yoffie, 2007; Gawer, 2009; Gawer \& Cusumano, 2002; Iansiti \& Levien, 2004; Kim \& Mauborgne, 2005; Williamson \& De Meyer, 2012). In short, for both $\mathrm{B} 2 \mathrm{C}$ as well as (originally) business-to-business firms, the literature has seen the move to the ecosystem model as a form of business model innovation, for which companies have surprisingly good visibility on what to do and how to get there. This assumption of good visibility even seems to have permeated work that has explicitly problematized the emergence of ecosystems, but which nonetheless has focused on samples of specific successful applications (e.g., Garnsey, Lorenzoni, \& Ferriani, 2008; Hannah \& Eisenhardt, 2015; Soh, 2010).

As a result, recent literature has suggested that it can present clear guidance on behavioral maneuvering to establish the ecosystem blueprint (see also Adner, 2012; Baldwin \& Clark, 2000; Edelman, 2015; Iansiti \& Levien, 2004), as we summarize in Figure 1. Firms clearly understand which assets they can leverage in ecosystems and derive a concomitant design of technological and social interdependencies by selecting the right partners (Adner, 2012; Adner \& Kapoor, 2010, 2016; Kapoor \& Furr, 2015; Kapoor \& Lee, 2013). Alternatively, they discover technologies and industry-level value systems or architectures as given sets of interdependencies in which they need to identify and occupy the strategic bottlenecks to attain control (Baldwin, 2015; Baldwin \& Woodard, 2007; Hannah \& Eisenhardt, 2015; Iansiti \& Levien, 2004; Jacobides \& Tae, 2015; Pagani, 2013) (Figure 1, arrow A). Having defined such control points for value capture, firms can build an internal business case for resource investment and create a set of appropriate tactics (arrow B). These, in turn, are applied (arrow C) to potential complementors and suppliers identified via strategic interdependencies (arrow D). These tactics would particularly aim to ensure synchrony (Davis, 2013) - i.e., that external partners will be producing those inputs required for the value propositions, and at the right time (e.g., Davis, 2016; Wareham et al., 2014). In this way, the ecosystem can iteratively build up momentum according to the rhythm of the focal firm (arrows $\mathrm{E} \leftrightarrow \mathrm{C}$ ).

In this paper, we argue that these insights need to be substantially extended before they can apply to companies considering establishing a new innovation ecosystem around a broadly applicable technology, such as a generative technology at the deep end of a multilayered industry architecture (Jacobides, Knudsen, \& Augier, 2006; Yoo et al.,
FIGURE 1 Ecosystem Design According to Extant Literature

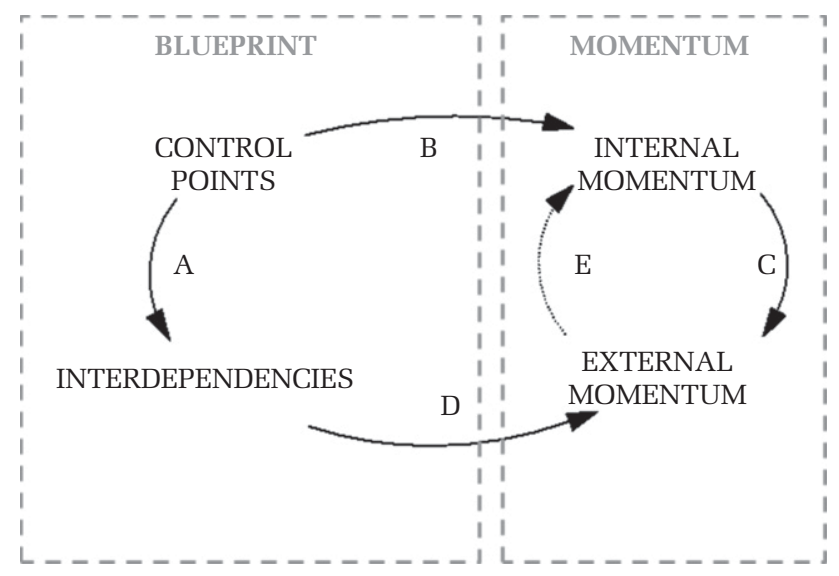

2010). The example of the IBM PC provides a case in point (e.g., Baldwin \& Clark, 2000; Bresnahan \& Greenstein, 1999; Gawer \& Cusumano, 2002): IBM, not exactly a B2C company, followed precisely the above blueprint-based process when designing the distributed PC architecture-a value proposition that was completely novel to the market at that time. The bottleneck IBM identified was the so-called BIOS, a piece that was quickly reverse engineered by other players-a move IBM had not anticipated. In addition, players chosen by IBM to join their ecosystem-first and foremost, Intel and Microsoftstarted their own maneuvering efforts toward a differently structured value proposition, eventually pushing IBM out of most of the PC market.

In our view, the IBM example should not be seen as a case of poor ex ante planning, but as representative of a general problem: in the linear, neardeterministic case presented by current literature, companies are seen to be able to define a priori where to make investments in such a way that couplings between parts of the ecosystem are maximized, and asset specificity is high. Hence, companies supposedly know ex ante how to achieve control, in particular by building or acquiring hard-to-circumvent complementary assets (Teece, 1986). Given the assumed accuracy of the blueprint, once the value proposition is in place, customers, complementors, and competitors will then have little other option but to play according to the rules set by the keystone player.

Conversely, we propose that once you go deeper into the technological architecture, such as when new technological breakthroughs are achieved, generalpurpose technologies invented, or standards to be defined, this assumption of visibility may need to 
be reconsidered (see also Jain, 2012; Le Masson, Weil, \& Hatchuel, 2009; Möller, 2010; Sull, 2005), for three reasons.

First, firms will find it hard to prespecify the value proposition, as, for them, ecosystem design implies processing endless combinations among unknowable options (Anderson, 1999; Dougherty \& Dunne, 2011). When no consumer-facing products using the technology or no information channels to the (yetunknown) customers currently exist, no single value proposition can be clearly determined to guide resource commitment. Second, given the uncertainty and contestability of the actual realization of the ecosystem idea, firms will struggle to find others to support it and make the required resource commitments (e.g., Ozcan \& Santos, 2015). Finally, even if the firm somehow manages to create the value proposition in the market, the assumption of prespecifiable, strong interdependencies and control points of the linear model does not need to hold, as highlighted by the IBM example: in any multilayered industry, in particular one built on digital technologies, once the value proposition is accepted in the market, players further downstream may discover alternate enabling technologies, allowing them to circumvent the original platform creator (e.g., Lieberman \& Montgomery, 1998; Suarez \& Lanzolla, 2005). As a result, even ecosystem initiators who succeed in getting to the market may find themselves left with a "fortress in the desert:" a set of preidentified control points and concomitant resource investments (possibly even by partners), which are now of almost no value, and which other players, some of whom the firm may have originally imagined to be "complementors" or "suppliers," will find easy to circumvent.

Consequently, in this paper we ask how a firm can simultaneously steer a collective process to discover and implement a complex value proposition via an innovation ecosystem while also ensuring that it will benefit from the fruits of the collective effort. We believe that this inquiry is essential to improving our understanding of how firms may successfully introduce novel innovation ecosystems that leverage the generativity of newto-the-world technology, and create entirely new markets around previously often unimaginable value propositions.

\section{DATA AND METHODS}

Given that the earliest stages of ecosystem creation remain largely unexplored in the literature, we follow a qualitative approach (Edmondson \& McManus, 2007). The aim of our open-ended inductive inquiry (Eisenhardt, 1989; Langley, 1999) is to disentangle the process dynamics of simultaneously creating and establishing control over an ecosystem when the customer-facing value proposition is yet unknown, with a particular focus on the causal structure of interactions and temporal feedbacks (Gioia et al., 2013; Strauss \& Corbin, 1998). To increase the external validity of our substantive theory, we use an embedded multiplecase study research design (Leonard-Barton, 1990). We follow a logic of literal replication (Yin, 2014) whereby we expect the identification of empirical regularities across contemporary cases to provide a contextualized explanation with a strong emphasis on theory (Tsang, 2013; Tsang \& Williams, 2012).

\section{Data Collection and Case Selection}

During the first phase, beginning in mid-2008, we engaged (Van de Ven, 2007) with 10 technologybased multinationals-from aerospace, automotive, chemicals, defense, electronics, industrial equipment, IT, and telecommunications-to learn about their perceived challenges with innovation ecosystems and the relevance of our research questions. This exploratory work included 25 interviews, usually with the chief technology officer (CTO) or a vice president (VP) including 11 interviews with the two companies selected for our case studies, a research workshop with one firm (three top-level executives), and a research symposium with four firms (nine toplevel executives).

In the second phase, which lasted from late 2008 to mid-2010, we focused our in-depth work on two of these 10 companies because of their suitability as objects of study, as well as our success in negotiating deep access at corporate level. For confidentiality reasons, we label our two case firms "Green" and "Red." Green and Red are world leaders in the IT and telecommunication industries, respectively. To cope with heterogeneous customer demands and enhance perceived value, both firms had to develop ecosystems to continuously innovate and upgrade their products and services. This data forms the core of our analysis.

For our literal-replication multiple-case design, we studied, for each firm, two recent and ongoing cases of innovation ecosystem creation. The embedded cases were selected among several ecosystem creation attempts we identified together with 
Green's CTO and Red's head of research. Other potential cases were too embryonic and, given the timescale of ecosystem creation (short of 10 years), a longitudinal study was not practical. We thus selected cases that were sufficiently advanced for our process research but which were nonetheless recent and ongoing, while ensuring our results could also explain all other attempts of which we had learned.

In addition, in the third phase from mid to late 2010, we conducted three final research workshops to check the internal validity of our preliminary findings: two firm-specific research workshops with each firm and a final symposium with key informants from Red and Green.

\section{Data Sources}

For our four cases, we rely on a combination of primary interview data and secondary archival data. We can draw on 48 interviews from Red and Green, including top-level and middle managers and core technical specialists (see Table 1). We took care not to lead informants. We did not follow a dyadic design, which would have included primary data from other ecosystem partners. Rather, we sought practical utility in our problem-driven theorizing (Corley \& Gioia, 2011) and focused the semistructured interviews on managerial agency in our case firms during the creation of these four innovation ecosystems.

We were permitted to record 21 interviews; we always took very detailed notes during and immediately after all the conversations, making sure to record informants' exact words. We wrote memos for each interview to adjust the interview questions as the research progressed, in particular to disentangle complex interdependencies and to get concrete accounts of who did what when. For all cases, we interviewed several informants multiple times to explore emerging issues. The lead author was present in 45 of the interviews, two interviews were conducted by the third author, ${ }^{3}$ and 31 were conducted as a team. The second author did not participate in the data collection, which allowed us to maintain the high-level outsider perspective required for informed and unbiased theorizing (Gioia et al., 2013; Mantere \&

\footnotetext{
${ }^{3}$ One interview with Green did not feature a member of the research team, but was generously shared by a colleague who had previously assisted us in establishing access to the firm.
}

Ketokivi, 2013). In total, we collected over 400 single-spaced pages of transcripts plus 200 pages of notes.

The secondary data amount to over 1,500 pages of all relevant strategic notes, reports, and market forecasts, as well as highly detailed specifications and licensing agreements for the different technologies involved. In addition, we gathered videos or graphical representations by various stakeholders of their envisioned ecosystems. These documents allowed us to capture both the origins of the respective ecosystems and how the way they were envisioned and evolved.

Our rich data allows us to follow a triangulation approach (Jick, 1979): by drawing on the same interview participants repeatedly, by cross-checking statements across interviews and across informants, and by verifying them against secondary data, we mitigated the risk of recall bias and validated the plausibility of their accounts. Further, we constructed four elaborate case narratives, which we circulated to our key informants. This led to the correction of a few factual errors, such as specific dates of events. In addition, the dedicated follow-up workshops with each firm (Red: 21 participants; Green: six) and a closing workshop (five top-level executives from both firms) in the third phase further corroborated the validity of our preliminary findings.

\section{Data Analysis}

We followed the method described by Gioia and colleagues (2013). As is customary in such process research, interviewing and analyzing initially proceeded concurrently during the three phases of data collection. This led to an initial list of first-order concepts emerging from the data. As we iterated between coding and data collection, our theorizing started to focus on two ideas: dealing with uncertainty and maintaining control over the ecosystem creation.

The first and second authors only began in-depth process analysis across the four embedded cases once all data had been collected and the case narratives verified. We discussed our respective interpretations, then refined the coding procedure and recoded the entire dataset at a more granular level to better capture how managers acted based on their anticipation of a fundamentally uncertain future. We then followed a process of constant comparison of first-order codes, grouped them into secondorder themes according to their inferred roles in the 


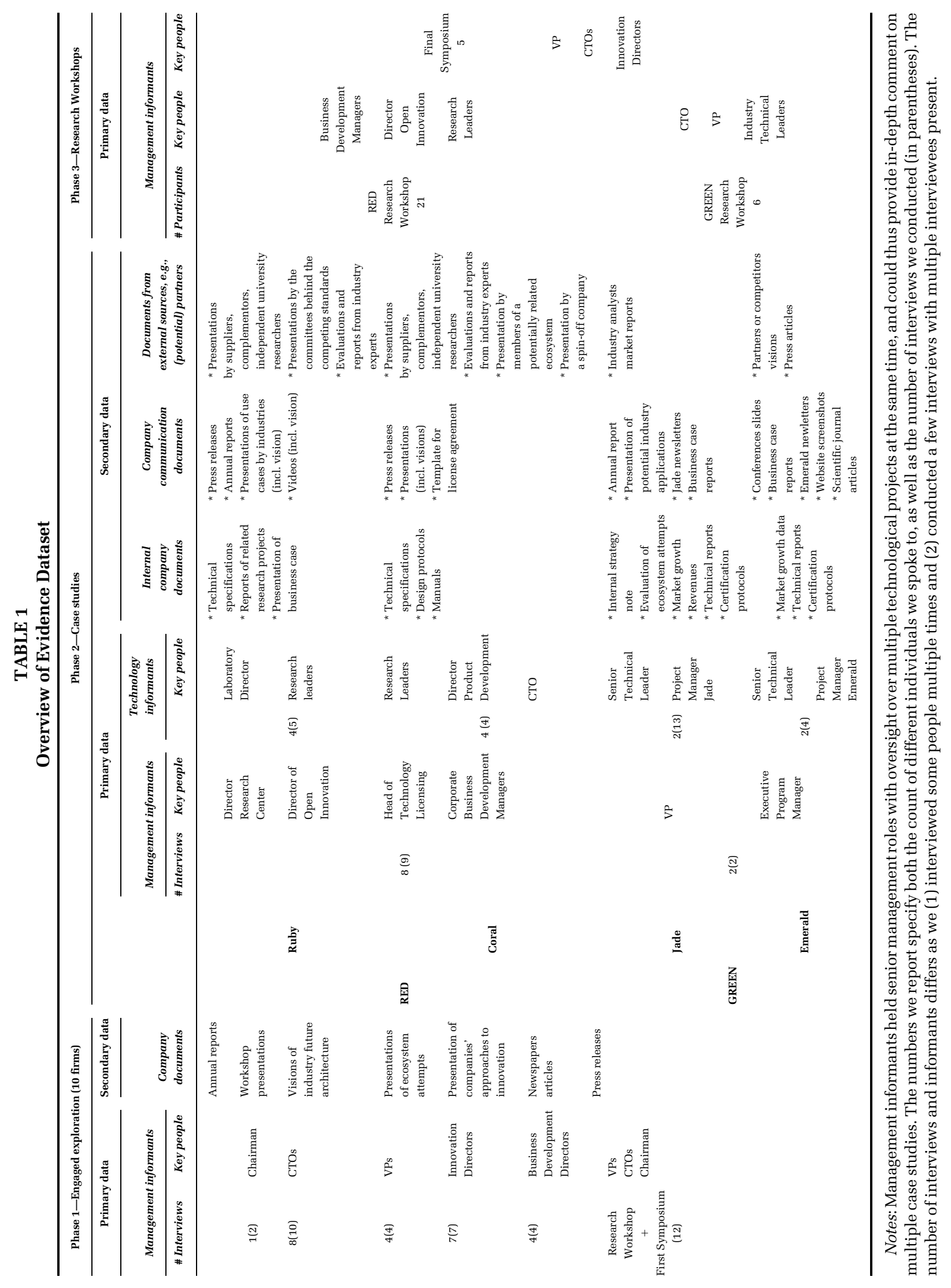


process, and synthesized them into aggregate dimensions. We then collectively went back to the relevant literature and cycled between the data, the emerging findings, and existing theory to check whether we had discovered novel concepts (Corley \& Gioia, 2011; Mantere \& Ketokivi, 2013; Strauss \& Corbin, 1998). We integrated prior concepts from the literature and the ones we discovered into a novel framework to reveal their relational dynamics during de novo ecosystem creation (Corley \& Gioia, 2011). This iterative analysis resulted in the data structure presented in Figure 2.

Finally, we used the data not only to induce categories, but also to generate a dynamic explanation (see also, e.g., Azoulay et al., 2010; Morecroft, 2007; Repenning \& Sterman, 2002; Sterman, 2000) of ecosystem creation. To do so, we identified causal links among second-order themes and returned to the data to confirm each link's existence and polarity. The themes and causal links among them, which are both tightly grounded in our data and internally consistent, form the feedback processes that generate the dynamics of ecosystem creation (see Figure 8).

\section{CASE OVERVIEW}

Before presenting our findings, we briefly describe each innovation ecosystem.

\section{Green-Jade}

In the early 1990s, Green developed a technology based on wavelength data multiplexing (WDM) compatible with their proprietary high-end systems. As fiber optics networks were being deployed, Green thought that one of many potential future applications for Jade could be to synchronize datacenters in metropolitan area networks. However, at the time this customer-level application required further technological developments in the deeper layers of the digital infrastructure. Green first developed a proprietary product that it sold to a few selected clients. This created a novel market. Soon, telecom equipment companies entered with their own products and rapidly improved the performance of the WDM technology, but their products could not fit into Green's high-end application. Green started to realize that, even if it was a "critical enabler" for this kind of higher-level value proposition, its WDM component was not part of its core business. Green would quickly become the "bottleneck" given the pace of innovation in this technology. In 1999, Green thus decided to meet with the four best telecom equipment companies and selected one as its singlesupplier for the component under a licensing and rebranding agreement. However, Green kept key aspects of the technology secret.

By 2003, the market was growing rapidly. Other equipment companies started requesting access to Green's technology to enter the lucrative high-end. As one of Green's VPs told us, the company's initial reaction was "no, why do we need you?" Yet, novel specialized applications quickly emerged in an increasingly heterogeneous market. Green realized that this heterogeneity created unexpected externalities with telecom equipment, drawing on which it could capture "revenue drags" by selling more of their high-end solutions to new clients. Green committed to this strategy, clarified its vision for the ecosystem, and licensed Jade to a limited number of partners. Since then, the ecosystem has grown to the seven largest telecom equipment companies.

\section{Green-Emerald}

During the dotcom period, Green noticed technological innovations in local and storage area networks that could lead to dense, scalable server systems with high-speed networking. However, the architecture for these compact, cableless servers did not exist yet. Given the development cost of an entirely novel platform and the lack of a reference from which to extrapolate market estimates, there was no business case. In 1999, a "skunkworks" team was allowed to explore the potential characteristics of such a system. Engaging with Green marketing and selected customers, they presented a business case to the executives in 2000, which led to a proprietary product in 2002. In 2004, Green started singlesourcing specific components.

Many unanticipated applications of economical high-performance computing emerged in areas such as finance, digital media, and decision support. Green realized that the broad range of new applications required a variety of advanced customer-end complements. Again, Green could not afford to become the innovation bottleneck. In 2006, sensing the addressable heterogeneity, Green drafted a possible ecosystem and decided to open its deep-layer architecture to specialist firms. With eight partners, Green created an industry association to promote this architecture, to manage the evolving specifications, to roadmap desired innovations, and to set up independent certification tests. By 2008, third-party vendors could develop and sell their own compatible 
FIGURE 2

Data Structure

First-Order Concepts

- A critical technology enabler

- A radically novel architecture

- Understanding the requirements

- Testing the design assumptions

- Uncertainty is so high

- Dreaming about the future/develop a vision

- Clarifying vision of what the system should do

- Economics of the game: multitude of uses/develop diversity

- Anticipated hub of the future

- Parts we want to keep for ourselves/family jewels

- Strong competencies (maybe not yet, but in the future)

- Leverage a position/control point in an area

- Need for complementary products and services

- Need to bring innovation to address heterogeneity

- Leave to others what is not important to us

- Go outside the company

- Need to work with many partners/ecosystem arrangements

- Developing an internal business case

- Selling the project to the main lines of business

- Aligning expectations of many internal stakeholders

- Versatility in products/faster reaction to new requirements

- Demonstrating the interest of external companies

- Selective collaboration/how they see it

- Bring along partners without misleading them

- Engage few selected customers to test the vision

- A vast market; an opportunity with no solution yet

- High enthusiasm among early participants

- Partners looking for volume/access to clients

- Enabler for their own markets

- Convince others/drive towards a common vision

- Market power of the company

- Channel the environment in a direction you can profit from

- Voting power over architecture specifications

- Vetting of partners/certification processes

- Inter-lock meeting/sharing of roadmaps

- Showcase days/forums/scanning

- Joint-review boards, architecture review boards

- Synthetic view of technical trends and directions

- Requirements and specifications evolved based on feedback

- Changed the influencing tactics

- Things turned out differently than initially planned

- Changed the business case for the ecosystem
Second-Order Themes

Aggregate Dimensions
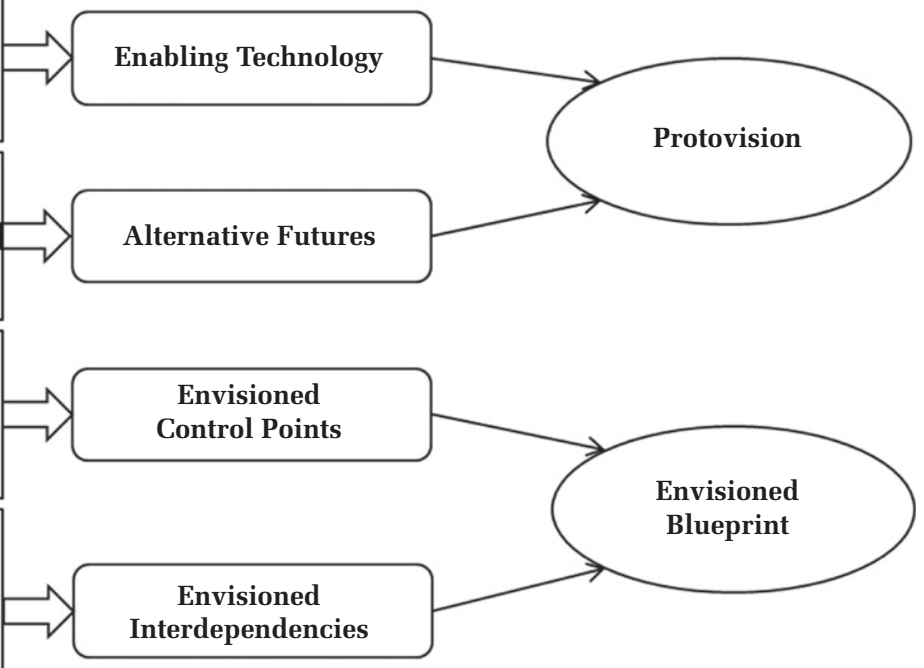

Interdependencies
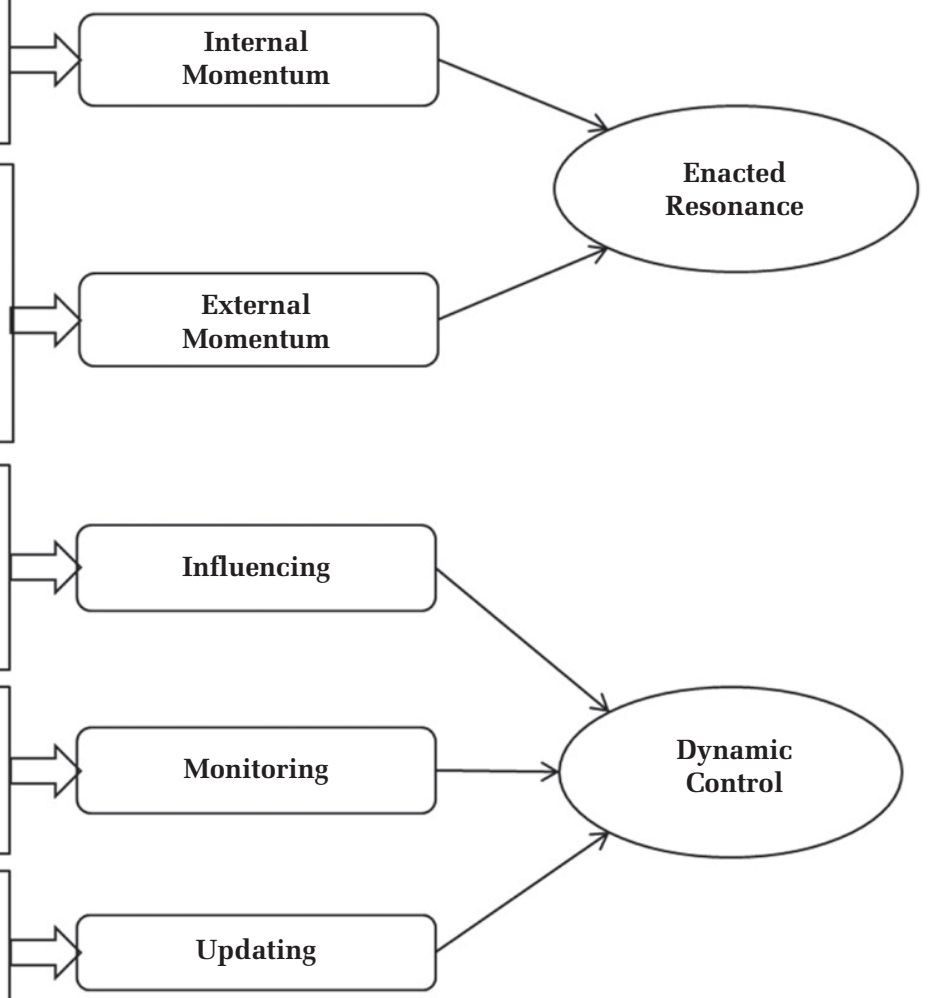
products. Green "never foresaw the impact [Emerald] would have on datacenter infrastructure." The ecosystem has since grown to over 100 firms offering components for specific applications.

\section{Red-Ruby}

Around 2001, Red researchers "had a vision" that the mobile phone may one day play a central role in providing connectivity to a multitude of sensors, accessories, and specialty devices. The company imagined many distributed sensors would be collecting real-world data to create new user-level services. Given technical constraints, these sensors did not yet have the underlying connectivity to directly transmit data. A new enabling technology was required to transform the mobile phone into a true gateway. Red started preliminary discussions with engineers at two companies specialized in small devices to learn about the processing and communication needs of sensors in these devices. It also asked them "what do you think?" and "could this be of interest to you?" With these companies and two universities, Red researched the requirements and initial architecture for the technology. In 2004, the whole Ruby package was functional.

During these collaborations, Red realized that its mobile-phone-centric vision was still appropriate, but the use cases that had emerged were different from those anticipated. Between 2004 and 2006, Red and its partners launched another research project to imagine future use cases for context awareness and to develop the required sensors. Internally, Red's business lines had not been interested in integrating Ruby in their products. Red's strategy was shifting: the proprietary business case for Ruby was dropped. Ruby was rescued in 2005 by a business development team, which instead imagined a licensing model-for which they obtained lukewarm support from Red executives. Ruby managers tried to win over small-devices firms to set up an ecosystem of connectable devices. For two years, Ruby managers performed a "balancing act" to convince both their internal stakeholders and selected external partners to commit to Ruby, and of simultaneously clarifying their vision for the ecosystem of user-level devices. By the end of 2006, Red had gathered 14 small-device firms and was receiving just enough licensing fees to cover coordination costs. However, the large semiconductor companies were still needed to create a complete ecosystem: Red managers made changes to the deep-layer technology and updated the licensing agreement. At the end of 2007, through a successful "poker move" the Ruby ecosystem was merged into an existing consortium favored by the dominant firms. By 2010, Ruby, for which Red owned key patents, was at last available as an enabler for the "Internet of Things."

\section{Red-Coral}

In the early 2000s, Red realized that its product architecture had become so monolithic and tightly coupled that Red's product development had to predict its future products' specifications and indicate clear requirements to semiconductor suppliers five to six years ahead. This rigidity created a lock-in situation, preventing the integration of innovations that emerged close to product launch. At this stage, "nobody wants to touch it anymore. Because when you actually get that kind of animal to work, you can't touch [it] anymore.” In 2004, Red started the total redesign of its system into a modular architecture to facilitate the (even ad hoc) integration of innovations by multiple vendors. At the end of 2005, Red had developed the basics of its Coral architecture.

Red rapidly understood that the success of Coral required more than solving deep-layer technical issues. The overall approach of sourcing components from third parties and integrating user-level functionalities would only be successful if the technology vendors were adopting Coral as well. In 2006, Red visited 15 companies worldwide to present the importance of Coral in a "horizontalized" industry. Red was probing these vendors' reactions and obtained initial commitment from 10 companies to experiment with pilots. As Red's strategy was shifting away from being a pure technology firm, it did not perceive Coral as a direct source of value capture but rather as an enabler for its future differentiation strategy. Given the ecosystem it could envision, Red decided to transfer the technology to the vendors under an open license as a preemptive move to prevent anyone else owning this "architectural control point." From its vantage position, Red collected feedback and acted as the editor of the vendors' requests for changes in the core. By the end of 2007, Red took the unilateral decision to freeze the Coral architecture. From 2008, Red began building up momentum around Coral by launching a website, organizing conferences, and talking to its direct competitors to get them onboard. As new sensors and connectivity, such as Ruby, became available, it became clearer that the Coral multilayered architecture and its 
service-level APIs could enable many "rich context services."

\section{A PHENOMENOLOGICAL MODEL OF ECOSYSTEM CREATION}

Against the backdrop of the case events sketched above, we found that the process of ecosystem creation, with a timespan short of a decade, involved a much higher level of uncertainty, reciprocal commitment, and ongoing adjustment than has been depicted in the literature. Across Green and Red, several informants described the different phases of "developing a new ecosystem that doesn't currently exist" as "an ecosystem game." The head of business development at Red described the challenges of ecosystem creation as a

very difficult question: it's both a creative process that you think creatively what can be done but then it's also in the management roles: if you don't know what you want to reach you can’t deploy.

Given the timespan, the uncertainty, all players' creative agency, and the increasing path dependency, we found that ecosystem creation requires a dynamic approach:

So you kind of have a long-term role in your mind and in the end it's, you know, "what's the game?" We're in this fast-moving services-driven business, it's more like poker. So you create options for the future businesses. There's always a new hand coming [...] it's a very organic model. (Red)

Below, we describe the inception process common to these ecosystems. We explain how an initially broad protovision crystallized, through mutual engagement and increasing commitment, into a more clarified blueprint of interdependencies. In this context, our findings show that the creation of a de novo ecosystem is an ongoing process of managing coupled feedback loops. Some feedback loops entrench the ecosystem trajectory by narrowing the range of alternative futures, forcing the focal firm to keep up with ecosystem dynamics, roadmapping or preempting positions, and enacting resonance among internal and external stakeholders. However, other feedback loops cause the ecosystem to drift unexpectedly, dissolve the emerging blueprint, and threaten the firm's future control points. We now demonstrate these fundamental feedback loops, which we progressively capture in Figures 3 to 7 , and bring together in Figure 8. Appendix A contains further details and lays out how Red and Green attempted to exert dynamic control in each phase.

\section{Narrowing the Future}

In the four cases, the inception of the ecosystem can be traced back to the late 1990s or early 2000s, but it took five to 10 years to build an innovation ecosystem. In the cases of Emerald, Ruby, and Coral, it was the perception of plausible future applications or "use cases" that led the firms to develop the foundations for the required technology. In the case of Jade, the process started with a technological innovation at the infrastructure level upon which Green managers imagined an initial service-level application. Still, in all cases the managers described each technology as a critical "enabler" for many potential service-level applications, which were embedded relatively deep in the sector's technological architecture, facilitating and supporting a sheer, limitless set of functionalities that could eventually be bundled to customer-facing offerings.

For the other companies WDM was a core business, for Green it was an enabler. . . an enabler for this whole solution ... an enabler for larger solutions. (Green Jade)

The current economics of [Emerald] technology enable these IT organizations to launch new business applications in a timely, competitive, and costsensitive business environment. (Green)

You are able to create, distribute functionality [...] between modules [in a way] that was not possible before. So this kind of technology enabled this kind of disruption. [...] It's a key enabler [...] for solutions with many different pieces, kind of Internet-based services components and diverse clients. It enabled new players to provide the technologies to that architecture. (Red Coral)

This technology was an enabler for new functionalities in consumer goods. (Red Ruby)

Although everyone recognized the potential of these deep-layer innovations, these enabling technologies opened up a broad range of possible service-level applications far into the future with no indication of what, where, or why the firm should prioritize at present. As stated by one manager, they were faced with a "mind-blowing space of exploration." Managers said they were "dreaming about the future" when trying to articulate initial protovisions: a space of connected future options enabled by the technology that seemed both feasible as 
well as potentially lucrative to the focal firm. Yet managers knew just how uncertain these protovisions were:

It's very complicated to think about options when you don't even have the first step, but you need to go there thinking what is the domino effect. If I do this where could it lead to? Uncertainty is so high that even if you do great options analysis as desk study, it's still about how you execute. (Red)

Understanding the limits of their own knowledge, managers tried to engage with selected trusted clients and potential partners to probe their perspectives. Green managers used this feedback to hone in on more specific applications and integrated the required features into proprietary products, although the development teams had to "pull together imaginative solutions to address areas that had not been anticipated." Red managers engaged with some external partners, whom they could project into a range of alternative futures, to understand the technical issues to be addressed across the "very holistic concepts created by [Red]:"

Research in context awareness and [Ruby] started maybe [in] '98. [...] We wanted to understand what are the requirements for [Ruby] technology [...] and what are the typical use cases they envision in the future. We had this sort of vision in 2001. The vision was somehow embedded in the requirement of the use cases we have, and then that's derived to do a kind of a more detailed specification for the work and so on. (Red Ruby; emphasis added)

We started this kind of research base collaboration already, so that we get all the feedback. We can introduce the concept, they have time to learn it and to build some demonstrations, together with us, and do some prototypes. (Red Coral)

Such engagement with partners narrowed down the range of potentially valuable and connected alternative futures. In essence, similar to the logic of abduction (e.g., Dunne \& Dougherty, 2016; Mantere \& Ketokivi, 2013; Peirce, 1878), managers understood that they could not predict one future value proposition, but that they could make efforts to reduce the uncertainty associated with their protovisions and iteratively discover whether they remained a possibility. ${ }^{4}$ Thus, while

${ }^{4}$ As Peirce (1878, cited in Locke, Golden-Biddle, \& Feldman, 2008: 907) originally put it: "deduction proves that something must be; induction shows that something actually is operative; abduction merely suggests that something may be" (emphasis in original). neither specific nor final, the emerging protovisions gave increasingly clearer direction for developing the technology in such a way as to arrive, potentially, at an even narrower range of future applications. At the same time, learning about intended as well as unforeseen areas of application allowed the firms to better understand what each enabling technology could be about, as well as how to potentially develop it further, to discover new, more refined applications:

We understood while doing the work that the most important use cases are different than what we anticipated at the start. [...] to be honest, when we started [we had] some assumptions about the use cases, and we were totally wrong... because the time span is so long that when we started in 2001 and then the technologies [will be] adopted [until] maybe [...] 2009, 2010, [we had] certain assumptions about [what] the future will look like and how things [will be] operating at that time. (Red Ruby)

The state of development of these enabling technologies was coextensive with the range of imagined futures. An unbounded range of alternative futures decreased the state of an enabling technology relative to the implied requirements. Conversely, as an enabling technology evolved and its tradeoffs became clearer, path dependencies limited its generativity and the range of plausible futures narrowed down. Figure 3 captures this nondeterministic reinforcing process.

\section{Shifting to and Keeping up with Ecosystem Dynamics}

With the deep-layer enablers progressing and the range of alternative futures narrowing, Green and Red managers attempted to explore how their companies could pursue these opportunities.

The objective is not to discuss the technology because the technology is there, but to actually imagine and design what the business model can be, what is the value proposition and who pays for what. (Green)

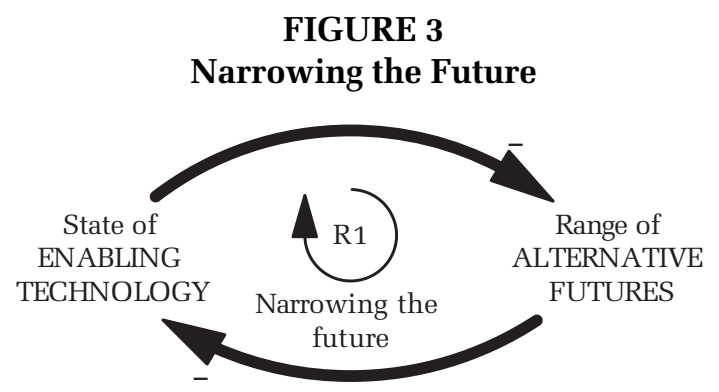


So the technology was there and we started thinking about, what can we do with this, the value proposition [...] we perceived there was value in [it] but we didn't know how to proceed with [it], how to get [the technology] out there, to create value with [it]. (Red)

Interestingly, neither company started with the idea of creating an ecosystem. Rather, across Red and Green it was the demonstration of an external pull from selected external partners that convinced internal executives to switch to an ecosystem model. To enable the switch, Red and Green managers had to create drafts of their envisioned ecosystem blueprints. These, however, were not deterministic implementation guidelines, but vague and living documents that still had lots of blanks regarding what value was to be created eventually, and how to capture some of it.

For both Jade and Emerald, Green had originally introduced a proprietary product. With its wider diffusion heterogeneous applications and customer needs emerged, which each required unanticipated technological developments. These externalities forced Green to realize it could not remain the "bottleneck in the innovation process." Thus, Green carefully selected suppliers to single-source the design and manufacturing of specific components around the protovision. Yet, Jade customers, who "want to have some ability to cause competition to drive prices down," started saying that they "like freedom at least to have pieces of this puzzle where we decide who will be the vendor." For Emerald, emerging applications also required specialized components in which Green had little expertise. As a Green VP told us, in both cases these interactions "led to the dynamic exchange of new ideas and rapid market learning" and the realization that "certain features can only be delivered with all companies working together." This increasing pull from external firms convinced Green executives to adopt an ecosystem model.

At the same time that customers were demanding more choice, other companies were approaching [us] with interest in forming their own partnerships, including access to their WDM innovations in exchange for both [Green's] technology and marketing support. (Green)

People do come along and knock on the door and say, “can I play?" [. . . W We weren't set up to deal with that and so that helped motivate us to go into an ecosystem. [...] By licensing our technology to multiple vendors [...] we were able to address emerging customer requirements. (Green Jade)
In contrast, Red managers had to actively build this external pull. Given Red's strategy at the time, existing business units resisted embedding Ruby or Coral into their product lines, so Ruby and Coral managers could not demonstrate business cases to develop proprietary products. Red managers themselves could not yet "see exactly how we are going to earn more money by selling those." As Red executives were "stopping the whole thing," Ruby and Coral initiated the switch to an ecosystem approach, even though they could not yet clearly envision what it would be:

The [internal] response we got was [.. .] "over my dead body!" [.. .] So then we just started building an alternative model for it. Based on the discussions that [informant] had started with external stakeholders, it was clear to us that there was interest; we weren't the only ones who thought that [...] there was value in this type of technology. (Red)

Ruby is an example of where we thought that, "yes, we need to build the ecosystem" [...] But we cannot identify what is the ecosystem of that, who would be the players there, and, therefore, we cannot convince our management to go with that plan. (Red)

At this stage of the inception process, the key question became "how do you actually make it happen?" A Red manager described that at that moment, and with no clear blueprint in hand, their "strategy was more, well, let's see what happens." Specifically, Red managers started presenting their broad protovision to external companies. The aim was to probe their interests, to refine the envisioned blueprint, and to convince these externals to commit some initial resources by highlighting how emerging interdependencies represented business opportunities for those firms-as Red hoped to delay its own commitment until a clear opportunity emerged.

Many people say that when you mention the word ecosystem you are already in trouble; it's not an easy business. You need to convince others to do their own businesses [sic]. (Red)

What I was actually trying to do was present a vision, the mobile phone becoming the hub for devices communicating with each other and to the internet and then telling them there's hundreds of millions of devices potentially in the future which can do that. (Red Ruby)

The idea was that we basically convince them that this is interesting enough for them that they should actually put some resources on this one [...] then we try to obtain some reasonably loose target [...] so we had to sell the idea for them, because we were asking for 
them to put effort and money on this prototyping stage, without any promises on any business opportunities. (Red Coral)

Like Green, Red managers engaged with potential partners in a highly selective manner:

I talked to 10 or 15 . But I was selective, so I wasn't talking to everybody. I picked from each of the industries, the top three, like PC or sports accessories, watches... and I picked the two or three largest, biggest companies and talked to those. (Red Ruby)

However, not all external companies welcomed our firms' protovisions. Red's existing technology providers perceived the Coral-envisioned interdependencies as a threat to their existing business.

The discussions with the existing partners, strategic collaborators, whatever you call them, they were much more difficult, because they saw that this might harm their business [...], because it might change their business landscape. They were not on the forefront to try to put a lot of resources to work on this thing. (Red Coral)

Similarly, Red's large semiconductor suppliers initially resisted adopting the Ruby technology:

Through the discussions with the semiconductor vendors, we realized that those who were very entrenched into the [existing standard] technology and were manufacturing those chipsets, they felt threatened, whereas those challengers who were not manufacturing [existing standard] chips, that were not leading players in that industry, but wanted to be, were very interested. (Red Ruby) ${ }^{5}$

In our four cases, by showing the external pull from potential partners with whom they could envision collaborating across a range of alternative futures, our managers tried to convince the executives at their firms to play the ecosystem game and to support further developments.

You need to create the external pull and market pull, when you really need to collect together the different players, not just end customers but other stakeholders in the business who would have their own businesses and make the whole ecosystem possible. And I would say that the most important thing is to be able to articulate the internal business case. This is the key thing in your examples, like [Coral] or [Ruby]. (Red)

\footnotetext{
${ }^{5}$ Beyond our cases, Green presented a vision of machine learning to a manufacturer. As Green realized it could not build the business alone, and could not even coerce that firm into playing ball, it ceded this opportunity.
}

In order to convince our product lines we need to go outside the company to find these. . especially product brands here, [famous brands] and whatnot, whoever those companies are, and get a tick in a box to get them to say, that, "yes, it's important, we want to work with Red;" and then we established the link here between them and the product line so that our product line's got the visibility that, "yes, there are these external companies who want to have this." (Red Ruby)

With this switch made, it became immediately evident that Red and Green had to change their perspectives from predicting specific applications on their own to understanding and keeping up with ongoing developments around them, and what these meant for the companies' enabling technologies, so that they could continuously keep abreast of the emerging ecosystem dynamics.

We focus a little bit more in understanding what is going on in this development there, and trying to understand what are the most essential scientific typically challenging problems in that new ecosystem, where we can also kind of gain momentum by creating new technology enablers. [...] There are a lot of disruptive elements in there. So, that automatically influences [...] the value network. We definitely don't understand what will happen. (Red)

Building on these observations, Figure 4 shows the set of relationships we posit, and captures a preliminary reinforcing feedback loop whereby the initial commitment of resources by some external firms inscribed a certain, albeit unpredictable, direction to the ecosystem dynamics.

\section{Roadmapping and Preempting}

While the switch to the ecosystem model helped further narrow down potential applications and partners, uncertainty was still high concerning what the emerging ecosystem blueprint, out of a broad range that remained plausible, would be. Even though our managers did not yet know what value they would eventually create with the ecosystem, they still somehow had to define their firms' ability to create and capture value in the future, in order to: (1) know where to steer development of "their" ecosystem (a process we label roadmapping) for eventual value capture; and (2) identify unwanted developments of others' value capture in their ecosystem and prevent them from taking shape (preempting). As we show below, these dynamics helped clarify a suitable distribution of roles for an increasingly narrow envisioned blueprint, so that 
FIGURE 4

Shifting to and Keeping up with Ecosystem Dynamics

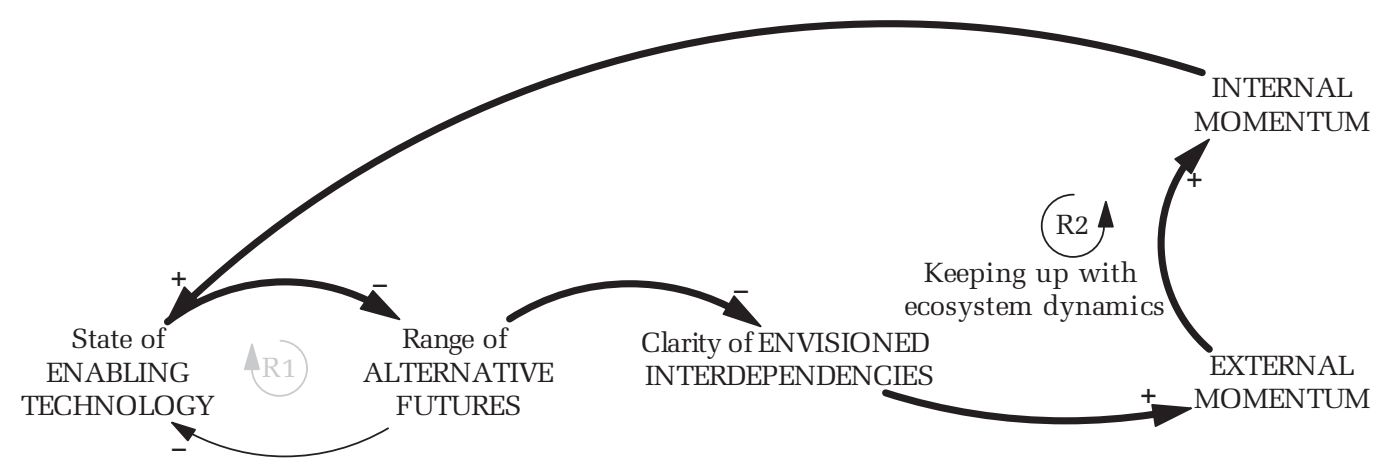

ecosystem players could further converge toward one common vision.

Managers quickly realized that the switch to the ecosystem model required them to give up on the idea of complete proprietary control that had driven many of their initial developments: while ownership of the entire system required for delivering a value proposition would be the best way to control the direction and rate of innovation and, ultimately, value capture, market heterogeneity and resource constraints forced the focal firms to make strategic tradeoffs:

Interviewee \#1: "The best way to do it is to own everything from end to end, to be perfectly honest."

Interviewer: "But what does ownership bring you?"

Interviewee \#2: "You can do whatever you want."

Interviewee \#1 (at the same time): "Control."

Interviewee \#2: "If I decide I want to introduce [technology for Jade] this year, I will introduce it. I don't care what anybody else says. I set the agenda. There are tradeoffs that you make on flexibility with respect to development investment vs. control. [. . . ] If I had the money to do that, I would do everything from end to end. The question is how much control do we want to take on that? (Green)

To gain value from the ecosystem game, managers told us that they would need to identify and capture control points, which one manager described as "critical points [where] most of the value is created through your position." They also understood that these control points had to be a moving target (Pagani, 2013; Tilson et al., 2010): in contrast to existing management literature (e.g., Adner, 2006, 2012; Baldwin \& Woodard, 2007; Williamson \& De Meyer,
2012), we find that the identification of future, defensible bottlenecks or control points through roadmapping was not static, but was continuously inferred from the crystallizing blueprint, dependent on the firm's strategy and available resources at the time, and not necessarily linked to direct value capture.

Specifically, managers were faced with a catch 22 : without knowing what the future value created would be, they could not make reliable investments in the present to make both value creation and capture happen. Yet any investment they would make to create that future may have turned out to be incorrect, given they could not know the full space of potential future ecosystems at any point in time. Indeed, given the timescale and the level of uncertainty induced by the creative agency of multiple actors during ecosystem creation, managers expressed that they had to carefully evaluate the risks of false positives and negatives in identifying future control points:

I don't know that you knew for every part of it what was, you know, 10 years from now going to be attacked or not. But it was clear enough what we were trying to do that you could say to me "we could go have people go do these things." (Green)

Whenever you do that, there's always a, "well, hang on, is that going to wreck our business?" I mean, we've got to just, kind of, check that, right? (Green)

You never know what happens during the 10 years. There is always new technology coming which will disrupt the old technology. Are we betting now ourselves [on] a technology which will come to the device in 10 years? We don't even know if Red will exist in 10 years anymore. (Red)

The course of action chosen by managers in this situation is again reminiscent of abductive search: 
rather than backward-inducing one chain of action for the present based on a clear vision for the future, they tried to further narrow down the range of promising possible futures, including vague control points, based on their revised understanding of the generic enablers and the reduced set of heterogeneous applications. As some managers explained:

In an ecosystem, I'd want some control points, some leverage. Anything that would be at the center [...] would have to have the attributes of [Jade] to hold it together as an ecosystem. You don't have to develop all the products in that ecosystem; you can actually have other companies do that. You still maintain control and have the ability to get the bulk of the revenue. (Green)

This type of [Ruby] technology [...] enables the mobile device to be at the center with some kind of device ecosystem. That was like the strategic thing there. At the time we also were placing a higher priority around the device, like a hardware ecosystem you could build around a device. (Red)

Put differently, the technology and the initial external partners created some initial direction for the ecosystem, and provided guidance on what value creation could roughly look like. Managers then triangulated this information with company strategy to project the corridor in which ecosystem and strategy would overlap in the future to understand what value capture could look like then. For example, Red was shifting away from being a hardware company and attempting a move to become a service-level company. This rendered the proprietary models initially developed for Ruby and Coral obsolete and led Red on a search for new control points:

[Previous approach] is a very effective process to sort of railroad the future in certain areas when you're changing a physical [component] ... this is all good in what Red has traditionally been excellent at, up to now. Red in the last years had this kind of change in direction 180 degrees very swiftly. All those competencies are still very valid, but they're a subset of the future competencies that are needed. How do you apply standards in services and software? Is it really the way you control the way it goes? (Red)

Similarly, Green switched to an ecosystem approach for Jade and Emerald at a time when its corporate strategy started to refocus on core businesses; to limit development resources; and to emphasize revenues from intellectual property (IP). For Green managers, the ecosystem dynamics that had been triggered were also highly uncertain. Nonetheless, they attempted to infer the future control points based on their previous engagement with external partners:

We did go down a path with kind of a corporate direction to try to sell more IP. [...] So, I had the responsibility of identifying areas where we could build our IP revenues [...] and we're already deriving some IP revenue back from [first outsourcing supplier]. So, somebody said: “Well, why don't we open that up a bit more and generate some more IP revenue?” (Green)

The fact [was] I was constrained to certain resources and development expenses, kind of put in the corner to find a way. Right? And this looked like a very good way. So, I can't take credit for being: “you know what, we can do this.”(Green)

We did try to put some structure around this when we were first challenged to do it and I don't think we had visibility into what was going to be happening 10 years from now but based on what we'd seen happening so far in the market [. . . ] before we picked [first outsourcing partner] we [had gone] around and talked to the top people in the business, at the time there was only four or five of them. We [had] vetted with each one of them "what are you doing?" and so we had that as a knowledge base going in. That was enough for us to put structure on it and say "this is something we think we can do." So, we did a little bit of an industry survey is what I'm trying to say. (Green)

Thus, combining the vague future projections from the technology-application side with firm strategy allowed Red and Green managers to further narrow down the set of potential ecosystem blueprints and get an initial understanding about which range of these may be more viable. For these, managers tried to infer crucial future interdependencies, and which of these could become future control points: these were areas Red and Green would need to somehow establish and keep control over, while letting other companies do their own business around them. ${ }^{6}$

At one point in time you sat down and put together a document that said here is this whole thing and here's where we have value and here's where there's IP. (Green Jade)

You have the access to that information, so definition of interface; that has been one point maybe of creating this ecosystem. (Red Ruby)

For Green, the decision over which parts in the envisioned ecosystem other players could do was

\footnotetext{
${ }^{6}$ We elaborate on the specific mechanisms of dynamic control in a separate section below.
} 
heuristically determined based on the strategic vision and resources available for development:

So, we take a look at how large an effort is it, at how strategic is that particular piece? How well does it fit within our scope in everything we talked about before, the manufacturing, all of the aspects of supporting of the product? And then we have to take a look at the business model behind it. So for example, if the decision is that it's not part of the core, or we can't afford to do it but we need it, then we start saying "what are the applicable business models that we have?” (Green)

Yet, some positions in the envisioned blueprints appeared as clear control points that Green would have to protect to ensure its future ability to capture value. As a Green VP explained, these decisions were ongoing as the ecosystem evolved and the blueprint clarified:

We sit down and figure out, "so what's the value of that? What's the downside of that?" I'm not going to sell someone, my competitor, part of my patent portfolio and then have them eat my revenue. If [Jade] is the nugget, then it needs Green to help make that. They can't pull it all together for a [Jade] solution without Green [...] now there are other parts that we can open, that we are still vetting and on our side it's quite a conversation. We have people who are looking at some of the IP and they say "we're not going to do that. We're never going to let anyone have this piece.” (Green)

Managers also construed additional control points by projecting themselves into the envisioned blueprints and looking at other aspects they might be able to control, such as architectural definitions, vetting rights, and certifications of interoperability to allow membership in the ecosystem. These control points had little to do with immediate revenue flows.

So even if, in the short term, we get squeezed out, I think we can come back and get additional value later. (Green)

Indeed, most of the future value capture was envisioned through complementarity effects. Green's goal was to create "revenue drags" from selling its own products and services, so that "you will make [X] dollars per year with the license, but you can make [3 $\times$ ] per year from the drag." By creating ecosystems of connectable devices and modular components, Red was building its differentiation strategy as it envisioned the horizontalization of its industry.

Our testing is basically cost recovery. It's sort of an enablement to sell our technology and we do profit from selling that technology, so that's another reason. (Green Jade)

Now when we create the open interfaces and open architecture, it will be so that the platform is [no longer] the differentiator at all, it is what kind of products you actually build, what kind of features, performance you actually use. That is actually the differentiation of products. (Red Coral)

Finally, these future control points had to be defensible, as other ecosystem players would inevitably try to circumvent them. The more Red and Green saw a potential to preempt such endeavorsthat they could be prevented altogether, or at least be detected and countered-the more they would shift their ecosystem visions toward that control point. For example, Green could validate its choices to "control who gets the know-how that's inside our core systems" when an existing ecosystem partner started questioning Green and "got it into their heads that it couldn't be too complicated to do." The vendor's engineers thought they ought to be able to reverse engineer a protocol and ripped one of Green's systems apart. They came back with a product that they requested Green test and qualify. After failing several times, they "tried various ways to weasel around" and to obtain the specifications without paying the Jade license:

We charged them for the testing, right! And they finally got frustrated and broke down and said, "okay, and licensed the technology." That was an interesting test of this model because if the stuff that we're licensing were obvious, or [...] easily reverse engineered, then I don't think the ecosystem would be stable because people would try to get the knowledge without paying for it. And if they were able to succeed in doing that then we couldn't charge for it, and if we can't charge for it we're not making revenue and the whole thing starts to break down. (Green Jade)

Similarly, both Red and Green tried to mitigate their dependence on others by preempting that others could establish strong control points themselves to gain disproportionate rents. With that aim, Green continued to work on Jade developments it did not intend to use directly, but which the partners would need for their future applications. Similarly, Red opened the Coral architecture to preempt any future in which an opportunistic player would own this control point.

You're always driving new stuff-that gives you a stable functioning ecosystem. So on [Green's] side let's have some people doing patents that we will 
never implement in our [product], but will have value if they're implemented over there because that will drive the ecosystem. (Green)

[Red] was moving to be a product and service company so we of course saw that we will not own the architecture, but we kind of wanted to make sure that there [was] no other company owning it [...], who would maybe otherwise make it a proprietary system. (Red)

This reinforcing loop whereby the focal firms infer future control points from the set of currently envisioned ecosystem blueprints and try to roadmap the development efforts to increasingly confine the ecosystem dynamics on a favorable path is captured in Figure 5.

\section{Enacting Resonance}

With roadmapping and preempting, Red and Green hoped to identify a direction for future value creation that could justify investment for future value capture in the present. To move toward actual future value creation (in which this value capture could thus happen), we found that Green and Red managers were trying to enact resonance: a reinforcing feedback loop leading to the amplification of reciprocal resource commitments between external and internal actors.

This resonance loop created increasing path dependency that reduced uncertainty and entrenched the ecosystem trajectory toward one clarified and shared vision. That is, different from existing literature where stakeholders can be selected and coordinated based on the future vision (e.g., Adner, 2006, 2012; Iansiti \& Levien, 2004; Williamson \& De Meyer, 2012), we found that it was escalating internal and external resource commitments, directed by Red and Green, that led to ecosystems emerging that were beneficial to our firms. Yet their actually realized structure had never been planned explicitly as such. Rather, we found that Green and Red tried to delay fully committing their own resources until the ecosystem had (almost) naturally locked in on a target that had emerged (almost) by itself.

Jade and Emerald already had internal momentum based on successful proprietary products. Green's commitment to the new markets had sent strong signals to the external firms that invested their resources once the ecosystem creation was triggered. Yet Green managers confirmed the challenge of convincing business lines by building external momentum:

Sometimes they [the main lines of business] have to be dragged, kicking and screaming, to the table. They say “we've not done this before." You have to get several different parts of [Green] swimming in the same direction for it to actually work and so we have to generate business and create the environment that they say, "this is good, this can continue." (Green)

Red managers faced this catch 22 from the start, and had to use "a balancing act" to bootstrap resonance among all stakeholders. For Coral, the architecture was perceived as a potential enabler for versatility and faster reaction to new user requirements upon which the future product differentiation strategy would be based. Nonetheless, Red's business lines only tentatively adopted the architecture for a very limited number of new devices. For Ruby, small-devices firms were convinced by the protovision and recognized the business opportunity for them in the envisioned blueprint. However, they would not commit to Ruby until Red's business lines

FIGURE 5

Roadmapping and Preempting

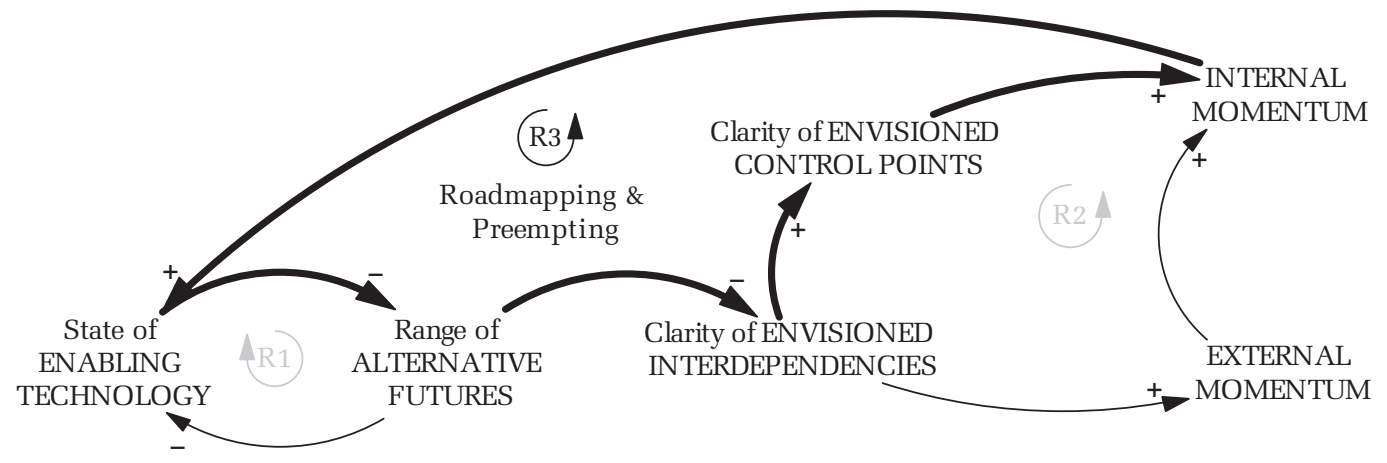


would commit to include them in their devices. Red's business lines would not commit to include Ruby in their devices until the semiconductor firms would commit to develop the necessary chips. Red managers felt they were facing "an unsolvable equation." As Red was changing its corporate strategy, its commitment had been more timid than expected by external actors:

I think that that was a disappointment to many of the consortium members, because watchmakers really were looking for volumes that [Red] would bring in, and the [device] supporting this would really be the enabler for their market, but there was no plan, even if [informant] and myself, we were planning that this [would] be in each and every [Red device] in some time, but when? No one knew. And, they were not interested within [Red], to even think about this, because they were saying, "when are the chips available?” No one knows. (Red Ruby)

As such, building internal momentum was not only crucial for receiving the resources necessary to engage in ecosystem creation and formation, it also signaled the focal firms' commitment and increased the confidence of external firms to join the de novo ecosystem. In turn, demonstrating that high-level firm executives supported the ecosystem creation helped foster external momentum. To achieve that, Green's top people interacted regularly with other firms, and Red used dedicated events to reduce uncertainty and tip commitments over a risk threshold.

You're getting your top people from Green interacting regularly with the top people from each one of those companies, which ought to be a fruitful thing to do, and if you recognize that as part of the process and encourage [it] then maybe new ideas will come up. (Green)

It was really a rolling ball; first you had a smaller meeting and people were a little bit afraid, and then when they were reassured by each other, by the next meeting they were more aggressive and then at some point. . . we tried to bring them together, so we took a bit of risk, we organized this rather big event. We had at least 50 people from like 20 companies invited to our headquarters. There we had an executive VP-very senior guy from our side-open it up and say "this is important technology for the future [Red];" and then, you had a lot of senior people from [famous brands] saying that "it was very important to us." (Red)

In turn, as service-level applications and the required interdependencies clarified, more intense collaborations were enacted with selected partners who had recognized the desirability of the envisioned blueprint. These initial "biggest commitments" by external partners were reciprocated internally and leveraged to amplify further external commitment:

It's just bilateral discussion with another company that we could develop a product or establish a business together, and then gradually we could take more companies, third company, fourth company there. And then it becomes a consortium... (Red)

It is an ecosystem game; just having the technology here doesn't make much sense, just having it there doesn't make much sense. They were all depending on each other, so when we brought them together and they all said to each other "well, yes, I think this is a cool thing," so that created a... the sentiment, the feeling, with everyone, "oh, well, this looks like it's really happening.” (Red Ruby)

Figure 6 captures this enacting resonance loop leading to the amplification of reciprocal commitment until the vision and ecosystem blueprint were clarified.

\section{Ecosystem Drift and Sliding Positions}

With the envisioned blueprint becoming increasingly clear, Green and Red had to account for the innovation efforts of external partners and to align their own development efforts. Ideally, following the above resonance dynamics, these resource allocation decisions further entrenched the ecosystem trajectory toward the envisioned blueprint.

We have to take a look at all protocols that we plan to support, and then we have to make the decision on our own investment for support of those protocols. [...] what is it that we want to drive from our box? When do we want to introduce the next bump on speed, or the next function that comes out? Because none of these are stagnant, so we have to pick and choose our own investment stream, and then align that with the vendors, and it's a very good case of that. (Green)

The part which we would like to keep to ourselves [...] first of all, [...] has to be of strategic importance for us ... our main business is important for us. And then we leave others to do something which is not so important for us. So it is according to our strategy and we are strong, we have strong competencies, maybe not already, but at least we know that, for example, because of research, we have an excellent team to work in that area. (Red)

At the same time, however, as summarized by a Red manager below, across the four cases initial 
FIGURE 6

Enacting Resonance

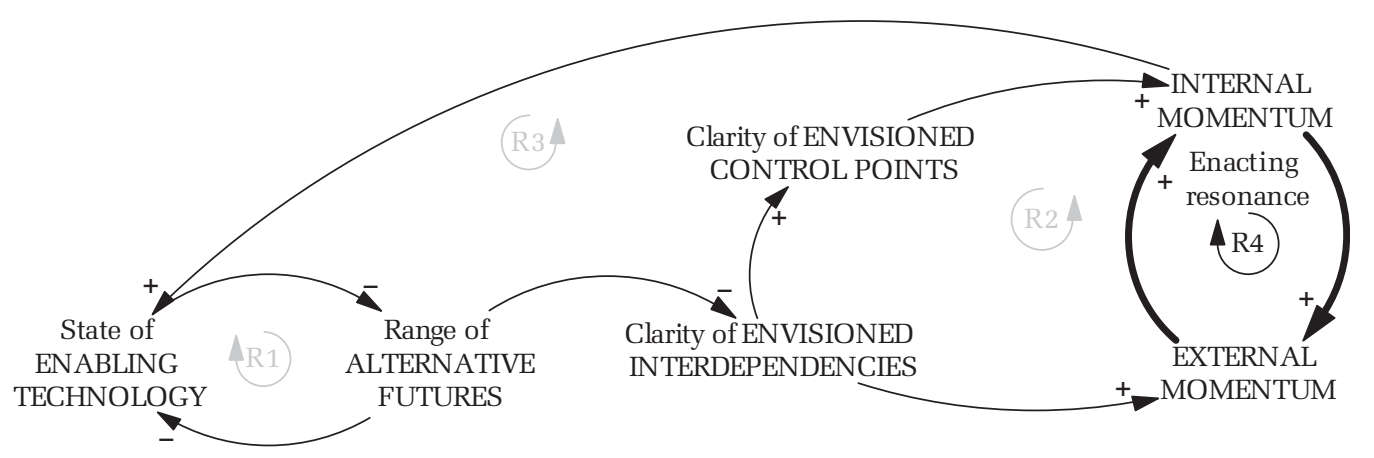

collaborations to explore plausible service-level applications, interactions to define requirements of the deep-layer enabling technology, early developments with a few selected partners, and increasing commitments to an emerging blueprint meant ecosystem creation had to be organic:

There are many points of view to this kind of steering. Let's say it's a team that consists of technology, business people, partnering people, marketing people, and they already have different drivers, and then the model that there are many different partners. So there's the whole package and then there are these individual companies inside there. So it's kind of, it has to be organic. (Red)

In turn, Red and Green had to realize that building momentum with external partners, whose creative agency is the raison d'être of an ecosystem, introduced stochasticity in enabling and enacting the scope of plausible futures:

Today's emerging nontraditional areas such as finance, digital media, and decision support change the concept of [application]. This change manifests a new paradigm [and] calls for new solutions that require definition in scope. (Green Emerald)

The risk is there that if people are not on the same page, [what you will be] delivering [and] what you are steering won't meet [sic]. (Red)

Such drifting of the emerging ecosystem dynamics, away from the envisioned blueprint, could naturally happen as new applications and interdependencies were discovered over time, and had to be accounted for. In addition, other firms (beyond circumventing the focal firm's coveted control points or creating some of their own) might even have attempted to purposively change the direction of value creation altogether by directly opposing the protovision and attempting to swiftly preempt its occurrence.

Such potential drifting of the anticipated value creation by the emerging ecosystem put Red and Green under threat that their anticipated control points were sliding, within the crystallizing blueprint, away from the emerging sources of future value capture. With ecosystem drift, other actors could maneuver to establish their own protovisions or even control points. Indeed, in our four cases, as more partners committed and allocated resources they also influenced the direction of the ecosystem trajectory: their innovations and creative agency increased the range of alternative futures. These competitive and often unexpected dynamics threatened the strategic value of the focal firms' envisioned control points and forced Green and Red to continuously evaluate the risk of the ecosystem drifting and their positions sliding within the emerging blueprint:

Somewhere down the line, within the next five, 10 years, I have no certainty that they will not do something that destroys my product and my product line. (Green)

So many options are valuable. So using a kind of new scenario to build the case and being flexible also to change the scenario when you get maybe stronger identities emerging. (Red)

Our analysis shows that two mechanisms passively moderated the drift. First, the risk of ecosystem drift was limited over time by a finite number of potential ecosystem partners: 
The amount of new vendors coming in, looking at the horizon, has decreased because we have seven and maybe there's only a handful left that are in this market. So eventually it will saturate. (Green)

Basically 2006 was just playing this ecosystem game. These guys, [informant], travelled all over the world and tried to get more companies on board. And I think in 2006 we then were able to get [large firms]. And those companies were basically... I think they represented something like $70 \%, 80 \%$ of the whole [application] market. So, these were the three big players there. (Red)

Second, as each enabling technology matured, path dependencies limited their further generativity and moderated the effect of external agency on the range of alternative futures:

While subsequent technical innovations remained significant, they were naturally less disruptive than the original products which created the market, and some of them were much more incremental advances in the state of the art. (Green)

Starting from 2007, there are more and more other companies that have taken the major role of defining the direction. So, we are not in the background, but there is less and less ownership because we think it is going the right way. (Red)

Figure 7 indicates how two balancing loops-B1, "ecosystem drifting" and B2, "sliding positions"counteracted the reinforcing narrowing, roadmapping, preempting, and resonance loops by reintroducing uncertainty in the ecosystem creation process. The creative agency of an increasingly large number of external players had the potential to dissolve the emerging blueprint and threaten the strategic value of the focal firm's future control points, even though these effects were moderated by an ultimate limit to external momentum and by strong path dependencies.

For an ecosystem blueprint to actually crystallize, we found that R1, R2, R3, and R4 had to strongly supersede B1 and B2. For example, despite recognizing the appeal of Coral and the strong pull from external partners, Red committed only timidly to the architecture, with "only one or two guys inside [Red] who were kind of guiding these 12 companies." Over time, some external partners who had adopted the service modularization approach maneuvered and took the idea into completely different areas, such that Red's initial protovision weakened.

[Coral ecosystem's] in a reasonable state, but it's not the lively ecosystem that we were targeting [. . . w when we started to do this whole ecosystem creation. (Red)

\section{Dynamic Control}

As we have seen above, legal ownership of future control points (such as IP) still held significant potential to contribute to future value capture. However, such static control was not sufficient to ensure value capture, given the long timespan and the creative agency of others.

Our analysis indicates that "winning at the ecosystem game" was about maintaining dynamic control over the coupled feedback loops constituting the emergent, uncertain, and collective process captured in Figure 8 (and detailed in Appendix A): managers had to continuously amplify the reinforcing loops, which crystallized the blueprint, and to counteract the balancing loops, which dissolved the blueprint, made the ecosystem drift, and undermined the firm's envisioned control points. Our cases demonstrate that the

FIGURE 7

\section{Ecosystem Drifting and Sliding Positions}

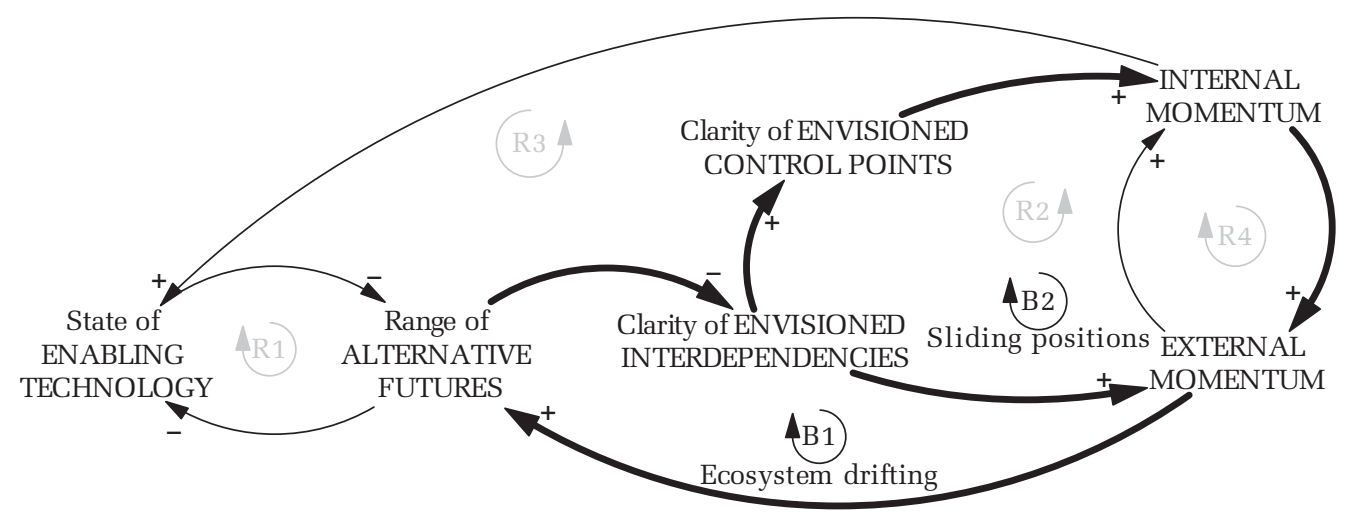


FIGURE 8

A Revised Process Model of Innovation Ecosystem Creation

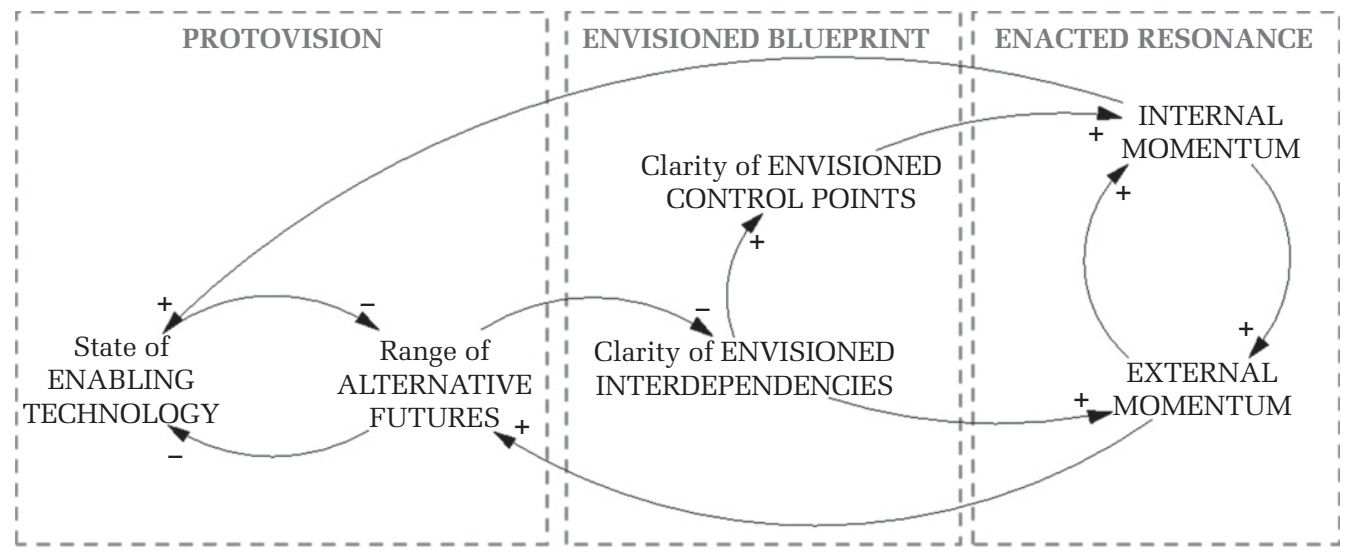

initially static approach to control based solely on ownership of specific assets deemed to be currently valuable broke down the moment firms entered the ecosystem game. Rather, strategic control had to become continuous, closed-loop, and targeted at the orchestration of collective action and the maneuvering of the focal firm.

This form of dynamic control over highly uncertain and collective processes was not evident, and challenged the focal firms in our four cases of ecosystem creation. As several managers explained to us, they had to learn to remain agile while maintaining control:

We've learnt how to, you know, migrate and morph into things that we need to. So, it's not like I have complete control, but I cannot lose total control. (Green)

This was one of the first success cases in this sort of environment, where we really started to create the ecosystem. We learned a lot about this ecosystem creation. We understood that sometimes $50 \%$ of the whole thing is this business development ecosystem creation, technology marketing; the sort of stuff we did not traditionally do in Red. (Red)

It was really kind of agile in terms of what we should do to really make this happen. We didn't have any really fixed plans, you know, "this is how we are going to make it happen and we're going to stick to it, no matter what." It was like, listening to the partners, listening to the internal programs, what their expectations were and then, you know, trying to keep it as holistically manageable. (Red)

Our empirical evidence highlights the classical challenge encountered by firms when they think about playing the ecosystem game: by relinquishing ownership over certain parts to external players in the ecosystem, they feel they lose the "ability to manage and control:"

As a matter of fact, I don't even have control on whether they're going to implement [function]. We lose the ability to manage and control, whatever the right term is, the delivery of that function on that particular component. That's what I lose. We are relying on it, we try to [have] influence. (Green)

Hence, managers enacted other dimensions of control that were usually subsumed in the concept. Specifically, to orchestrate the crystallization of an ecosystem blueprint while at the same time ensuring future value capture, Green and Red enacted three dimensions of dynamic control: influencing the direction of ecosystem evolution toward a clarified vision and coveted control points, monitoring the evolution of the ecosystems and likely realization of future control points, and updating strategies in case of mismatches.

Influencing. Managers used influencing mechanisms to narrow down the future, to clarify the blueprint and entrench the trajectory through increasing commitments, and to establish envisioned control points. These mechanisms amplified the reinforcing loops R1, R2, R3 and R4 and counteracted the balancing loop B1 and B2 (see Figure 7). Across the four cases, these mechanisms included company visits, workshops and events, discursive strategies, vetting of partners, qualification processes, architectural boards, arbitrage of roadmaps, market power, and preemptive moves. 
For each type of control point, there is an underlying power base. On the technological dimension, standards or de facto ones are strong levers. Can you build your ecosystem and create control points, or can you merely influence the unfolding dynamics? (Green)

What I mean by control is how you exert an influence in a way that you channel an environment in the direction that you know you're well equipped to profit. (Red)

Through meetings, workshops, or conferences, the firms attempted to imprint, in a performative manner, their protovision upon selected partners. Managers in Green and Red described this as a "persuasion game" where everyone is "depending on each other:"

The first part is getting everyone on the same page. The second part of the workshop is "if this is the architecture of the [protovision], then what is the role individuals have? What's the vested interest that people want to try and drive forward with?" (Green)

It's more a question of being clear about what it is you want to get out of it and really clarifying that as quickly as possible, so that you can bring along partners without misleading them; and in a way that drives towards a common vision of what the value chain will be. (Red)

However, through external engagement the vision was also evolving. Red and Green had to leverage other mechanisms to steer the ecosystem dynamics toward a desirable blueprint and limit drifting. In the Green cases, market power and direct access to the client were also possible; however, in the opinion of a Green VP, this is "an ugly place to have [...] influence." Other steering mechanisms ranged from the vetting of partners in the ecosystem, to trying to influence the direction of partners' roadmaps, to expensive certification processes, which partly influenced the timing of complementors' releases so as to achieve synchrony (Davis, 2013):

When the [partners] come to us and say we have this list of features, [Green] can tell them "these features are of good, bad or indifferent interest to us;" "I want you to qualify this, this and this immediately; these can wait until next year; this not so much”... (Green)

You could have three companies working on a camera module and they would each be talking to you but they will not be talking [to each other]. (Red Coral)

Both firms strived to retain their ability to directly influence the direction of innovation in the generic enablers. For Emerald, Green set up a weekly Architectural Review Board with editorial power to review the vendors' requests for change in the specifications. Red established committees for Ruby and placed its own people in key positions to keep arbitrage over suggestions for improvements to the enabling technology. Red had made Coral an open architecture but tried to influence the trajectory by being the most active contributor.

All the companies pretty well understood where we would like to go [with Ruby]. Of course, we still had all the ropes in our hands and we were pretty much in control. (Red Ruby)

Those who are most actively contributing own it, and there is no ownership by any other means, but if you want to develop it, then you have control where it goes. (Red Coral)

Monitoring. To be able to influence the ecosystem dynamics, it was crucial for both firms to know what was going on. Red and Green tried to get an informational advantage through broad scanning networks and leveraging some of the influencing mechanisms for a monitoring purpose. For example, Red used its conferences and showcase events to monitor generativity:

There is [another] innovation that is built on top of [Coral] but was happening outside. There used to be a so-called [Red conference] once per year, a big event [at which] different vendors could show their latest technologies under NDA to [Red]. (Red)

So then we do scanning. We scan what's available. It requires being present [via] the Internet, databases, colleagues, bankers etc. who are active VCs, trade shows. Meetings are very important. So you need to meet lots of people because it's a big world. (Red)

Similarly, Green took the position of a "neutral" broker in its Jade ecosystem. On a bilateral basis, Green exchanged roadmaps with each complementor, then synthesized and anonymously shared all information. Green gained an overview of all ongoing developments and updated its roadmap to anticipate potential dynamics. Then, by communicating its roadmap updates, Green could influence other players to align their innovation trajectories with Green's preferred direction.

All the vendors present to us their roadmaps. They also tell us what's the new feature and function that's coming. [...] As the keystone, we get the big picture. We synthesize that, we flush out things that are proprietary to certain vendors so that it can be shared and then we propagate that back to all of them and they get value from it. (Green) 
Green and Red managers noticed that ecosystem partners were also monitoring each other to see whether they were aligned with the ecosystem's evolution or could get a competitive edge:

As I told you, all these vendors are very competitive and they're always looking for market intelligence on each other and trying to find an edge. (Green)

Even though all this was confidential, some people just hear that something is happening, so there were all sorts of queries that they had heard that there is something new happening here. (Red)

Via their key positions in committees, both firms could also monitor the demands for changes to core technologies that provided valuable information about nondisclosed elements of the partners' strategies, such as their potential intent to migrate in the ecosystem blueprint:

The edges become fuzzy: your partners may become competitors. The challenge is to keep track of the dynamic externalities. (Green)

In addition, conversations between the focal firms and their complementors were not one-off, but ongoing. This allowed Red and Green to monitor and process, almost in real time, the direction and rate of change in their ecosystems, as described by a senior manager in Green:

It's not like we only do it when we have meetings, we talk to them informally on a regular basis; "what do things look like today?" Take the temperature of it. That kind of informal interaction is a tremendous benefit. (Green)

Updating. Based on the information continuously gathered through these monitoring mechanisms, the managers formed expectations about what could happen in the ecosystem given others' commitments. If they perceived a deviation from what they were previously expecting, they updated their influencing strategies (first order) or the protovision, the envisioned blueprint and coveted control points (second order). Regarding first-order updating, when first engaging with component suppliers Coral managers understood that modularity had various meanings for different people (e.g., software vs. hardware engineers). They changed their influencing efforts to "partly educate them." Coral managers also shifted their rhetoric to communicate Red's vision after receiving a lot of pushback when presenting Coral as a change in architecture:
Companies are built around architecture; we tried to "sell architecture," which meant you would have to change. So, we changed to "selling solutions to salient, tangible problems.” (Red)

Second-order updating became necessary when internal changes in corporate strategy or external information implied that influencing was unsuccessful or inadequate. Such changes led the managers to update their envisioned blueprints or coveted control points.

At the same time, the scenarios themselves [were] continuously updated based on user evaluation results and feedback from technology and application developers. (Red)

We had big ambitions in the gaming side at the time. We also had... at the time we had more vision around watches and all of that. I mean, you have to understand that things have changed over... the vision and strategy we have today is not the same as it was at the time. (Red Ruby)

Green updated the business case for Jade: it moved from selling a proprietary product to rebranding, then moved to a licensing model when it envisioned the ecosystem, and finally charged partners for its certification tests. Likewise, after realizing the heterogeneity of market segments, the Emerald team updated both the vision and the control points: they opened the specifications to enable vendors to respond to these very specific market needs.

The business case for Ruby was also updated several times. Initially, it was thought of as a proprietary technology, then it moved to a per-piece licensing model with its ecosystem partners. Then, as Red decided to no longer directly manage the ecosystem, it went for a "poker move" to be perceived as a threat so as to be finally absorbed into an existing competing standard. Yet, on entering the much-hoped-for merger, the business case was updated again:

The very first initial idea, at least internally, was that we thought that we would collect a license fee per [piece], from the [component] vendors, nobody else. But [it] came up quite early that it's probably never going to be possible. [Software multinational] would not accept it. So the very final change into the agreement before signing was that it was not a licensing agreement. It was a merger of two consortiums. [Ruby] was merged with [existing standard] and the compensation is not compensation for the technology. It's not a license fee. The compensation to [Red] is for having put the effort and the investment [into] 
building and creating the [Ruby] ecosystem, and gaining this wide acceptance in the industry, so far. That was to be compensated. (Red)

Nevertheless, several Red managers insisted that a hard core of the protovision remained intact:

It's kind of maybe capability that was really to change something, but always there is some kind of a hard core there, a fundamental innovation there that is not changing. We had basically the same vision that all parties saw a lot of value in the devices being able to communicate [with] each other [...] If the vision is strong enough, it will survive all the instability. This is a kind of acid test. (Red)

\section{DISCUSSION}

We set out from the premise that when creating new ecosystems starting from generative technological inventions-which are often deeply embedded into an industry architecture, or even yet-to-bediscovered-traditional models of ecosystem evolution and governance will struggle to provide guidance. Our data show that playing such an "ecosystem game" is a directed process in which firms orchestrate the crystallization of an increasingly clearer envisioned blueprint: they delay their own resource commitment to keep open the option space of desirable ecosystem outcomes, but act preemptively to veto undesirable futures. This process works through a series of coupled feedback loops, which ecosystem creators can influence through dynamic control. In doing so, actors try to influence, simultaneously, the envisioning and enactment of value creation and value capture. They drive, iteratively, present action to achieve clarity about what the value created by the ecosystem will eventually be, while at the same time trying to understand which control points they need to establish and defend now to ensure they can capture the lion's share of the value to be created.

\section{Implications for Theory}

Our findings allow us to make three key contributions to the emerging literature on innovation ecosystems and to broader discussions on innovation strategy and strategic entrepreneurship.

The first, naturally, is the conceptual model we developed. While we are not the first to have argued for a distinct treatment of early-stage ecosystems (see also Jain, 2012; Le Masson et al., 2009; Möller, 2010), to the best of our knowledge ours is the first comprehensive attempt to untangle how agents can drive ecosystem creation based on innovative generative technologies. In short, we introduce a phase of radical technology and market uncertainty before the current linear perspective of envisioning design (e.g., Adner, 2012; Gawer \& Cusumano, 2002; Iansiti \& Levien, 2004). In this stage, actors discover, rather than plan, the ecosystem approach, engaging in it only when learning about significant external interest. While the linear process may of course still "follow after" our model, our model may further explain cases with which that perspective currently struggles, such as the IBM PC case mentioned initially.

Our closed-loop model of de novo ecosystem creation is also reminiscent of the literature on dominant designs and first-mover advantage. ${ }^{7}$ When faced with high uncertainty, firms need to fear that irreversible resource commitments can easily be overtaken by a second mover (Suarez \& Lanzolla, 2005; Suarez \& Utterback, 1995; Teece, 1986). We find that our ecosystem creators devised a strategy in which, rather than trying to tackle this uncertainty head on by betting on one specific application, they distributed the explorative generation of alternatives (Gruber et al., 2008; Knudsen \& Levinthal, 2007) to their emerging ecosystem. Then, by abductively narrowing down the range of alternative futures (Dunne \& Dougherty, 2016; Reetz \& MacAulay, 2016), they hoped for clear signals and resource commitments from other actors in the system while ensuring they could strike as soon as they identified a valuable opportunity (Sull, 2005). Thus, our model explains that while actors delay commitment in order to keep the space of possible value creation open, they also act based on their anticipations of value capture to preempt undesirable futures before an ecosystem blueprint crystallizes. We believe that this distinction helps to reintroduce managerial agency and, as we elaborate below, clarify recent debates on process research in entrepreneurship (see, e.g., Arend, Sarooghi, \& Burkemper, 2016). In addition, we argue that such a design may hold general promise for when firms try to introduce novel generative, deep-layer, or general-purpose (see Gambardella \& McGahan, 2010) technologies to the market. The tactics we identified may thus also be of assistance to firms hoping to establish industry platforms or standards. In fact, the multilayered architecture in the context of our case studies

\footnotetext{
${ }^{7}$ We thank Professor Fernando Suarez for pointing out this parallel to us.
} 
simply highlights the temporal and applicative distances between a generative technology and the set of heterogeneous future value propositions it enables. Hence, in essence, our model has explanatory power in the more general case where technological generativity makes it difficult for a firm to determine the nature and range of such applications ex ante.

Second, by embracing the uncertainty necessarily inherent to ecosystem creation, we bring the "system back into ecosystem:" our model allows for a (systems) dynamic perspective on ecosystems, and, hence, for a bridge to that work (see also, e.g., Azoulay et al., 2010; Morecroft, 2007; Repenning \& Sterman, 2002; Sterman, 2000). The logic of dynamic control, our second contribution, must follow from this view in which a system can never be statically controlledexcept for the (as we would argue, rare) case of one firm owning the entire ecosystem. Rather, our model portrays ecosystem strategy as a closed-loop process where a protovision provides a general direction (see also Sull, 2005, 2007). To prevent control becoming episodic and fleeting, organizations will need to install control points into a nascent system (Pagani, 2013; Tilson et al., 2010) and to strategically navigate the process of discovering value creation to ensure eventual value capture.

The notion of anticipated control points in the emerging ecosystem blueprints relates to recent calls in the demand-side perspective literature on the resource-based view to endogenize the determination of a resource's value (e.g., Priem, Butler, \& Li, 2013; Schmidt \& Keil, 2013). What we show is the complexity of deciding just what a defensible control point is: the control point can only help with value capture in the future, if (not merely "when") value creation itself has happened, and only if in the way the firm anticipated. Hence, our process model turns around the temporality of value in existing discussions: our findings translate into the premise that value can only emerge from a value proposition that lies in the future, so that the value of a given resource or control point must be determined by projecting oneself into an image of the future, instead of extrapolating the past.

As such, value creation and value capture may, as in some of our cases, become fully separated, in that control can no longer be connected solely to fixed assets required to produce the focal innovation (Teece, 1986). Rather, dynamic control over the process of ecosystem emergence will draw increasingly on institutional and sociological devices (Thomas et al., 2014) that allow for influencing and monitoring. These dynamics will then steer the process toward intangible control points such as customer access, networking ability, or brand, all of which, at least conceptually, might even be amplified by waiving ownership on underlying assets (Alexy, West, Klapper, \& Reitzig, 2017). Indeed, in line with a growing body of conceptual work (Alexy, George, \& Salter, 2013; Tilson et al., 2010; Yoo et al., 2010), as well as insights from the linear ecosystems model (e.g., Gawer \& Cusumano, 2002), our findings suggest that strategically sharing IP may be essential to moving the future ecosystem toward where the focal firm would want it—or to at least limit directional change (see Stieglitz, Knudsen, \& Becker, 2016) to prevent drifting (see also Polidoro \& Toh, 2011).

Third, existing entrepreneurship literature, with its emphasis on value creation under uncertainty, has offered powerful insights on how to look at multiple opportunities at the same time and commit resources sequentially. Based on real-option logics, several authors have highlighted the importance of generating multiple alternatives (see, e.g., Gruber et al., 2008, 2013) and have advised managers to keep their options open over time, instead of committing prematurely to wild bets (McGrath \& MacMillan, 2000). Our findings extend these recommendations to settings previously characterized as "stepping stones" (McGrath \& MacMillan, 2000: 168-171, 2009: 61-62). These are the situations in which realoptions-based approaches should apply most, and yet are also the situations for which existing toolsets seem least detailed and their application most challenging. We argue that this may be because when technological generativity and market heterogeneity combine to form fundamental uncertainty, it may not be possible to grasp the nature of future opportunities; hence, managers may fall into the options trap (Adner \& Levinthal, 2004). As one of our informants stated, when managers face a "mind-blowing space of exploration," they are limited in their ability to construct the option space ex ante, and to identify clear assumptions upon which to design any experiments. Rather, we found our managers resorting to techniques similar to the idea of pivoting found in the entrepreneurship practice literature (Osterwalder \& Pigneur, 2010; Ries, 2011), in which they conducted iterative, abduction-like hypothesis testing. ${ }^{8}$

In this context, prior entrepreneurship literature has demonstrated the positive impact on performance of constructing and considering a broader set of potential applications, but also that, given

\footnotetext{
${ }^{8}$ Note that both of our case events and our data collection predate this literature.
} 
managers' bounded rationality and firms' control over limited resources, there are diminishing returns to constructing a larger set on their own (Gruber et al., 2008). At the same time, work that has tried to solve the latter issues by focusing solely on the resources a given firm has to hand to construct its future (Baker \& Nelson, 2005; Sarasvathy, 2001; Sarasvathy et al., 2008) has assumed that organizations are in the process of finding a goal. Hence, that literature has essentially negated the idea that clearly preferable versions of the future exist for the firm, that multiple organizations may be simultaneously competing to realize their preferred one, and that they will somehow need to influence others to commit their resources in order for any value creation and value capture to happen. In turn, our model may allow for a new perspective toward combining goal-oriented and processoriented models of entrepreneurship research in general, and corporate venturing in particular, in a way that entrepreneurship practice seems to have embraced already.

\section{Implications for Practice}

For practitioners, we provide insights into how to play the ecosystem game. Our model demonstrates that managers can leverage the generativity of an enabling technology by distributing the explorative generation of heterogeneous alternatives to external actors in the emerging ecosystem. This requires shifting managerial attention away from the sole focus on the control of current resources to a more encompassing concern for the dynamic control of ecosystem dynamics. Such approaches will require phronetic abilities (Nonaka \& Takeuchi, 2011) from the individual managers responsible for de novo ecosystem creation. As our data show, they are the ones who bootstrap the protovision: they get initial interest from a potential partner, come back internally to show that there is external interest, get some support from internal stakeholders, and meet other external partners and show them that they have obtained internal support for the technology and that they can make a commitment. As senior managers at Red explained to us, playing the ecosystem game well requires "excellent business development guys, who really find the way how to play the game in [new technological domains]," who "understand the complexities of that kind of approach," but who are "pragmatic, even though we are talking about the future."

These remarks resonate with McGrath's (2013) advice to managers that as competitive advantages become transient, individuals must develop strategies to acquire the competencies and the embedded relationships to work in "flux." Ultimately, the diffusion of the ecosystem model may lead to tensions in the current paradigm based on value captured solely through the legal ownership of assets. The ecosystem game, as a class of distributed strategies, may hence even prompt a new primary cycle in management models (see Bodrožić \& Adler, 2017).

\section{Limitations and Suggestions for Future Research}

Of course, our study is not without limitations. Our purposive case selection is biased toward large firms: to study de novo ecosystem creation, we focused on actors that have the market power and resources to credibly engage in such behavior. However, these factors need not be preconditions for the phenomenon we explain, as shown by our introductory example on Apple. Similarly, the multilayered IT industry we selected is known to promise particularly high returns from successful ecosystem approaches, and has thus been the focus of much work on ecosystems. Yet, in a broader sense, our cases studies are about the coextensive evolution between a protovision of a broad range of futures (with a core fundamental idea) and the development of an underlying generative technology. It is this generativity, spurring unexpected innovations by uncoordinated actors to address heterogeneous markets, that challenges the linear model of ecosystem strategy and the real-options logic (also see Tilson et al., 2010; Yoo et al., 2010). In turn, any industry that has generative potential may be, or become, subject to the dynamics we describe. Although it is difficult to pinpoint industries not affected by digitalization, we still call for replicative studies in less layered and less modular industry architectures (see Jacobides, MacDuffie, \& Tae, 2016; Yoo et al., 2010). Here, further work should investigate whether the fundamental uncertainty introduced by the temporal and applicative distances between a generative technology and a range of alternative futures leads to the same ecosystem creation dynamics as our model predicts. Currently, other generative technologies such as nanotechnologies, genome editing and engineering (such as CRISPR), or even microbiota therapies, broadly promise to enable an unbounded and as-yet undetermined range of possible futures.

Moreover, we consider five research questions that seem particularly promising to extend our findings. First, we call for studies on how an ecosystem "gets 
out of control" when the firm(s) initiating it can no longer steer its evolution or end up ostracized. Are such developments driven by firms' locking in too early on a vision, or by a loss of dynamic control?

Second, our findings regarding abductive search may open an avenue for new perspectives on searching and strategizing, in light of recent conceptual (Lord, Dinh, \& Hoffman, 2015; Reetz \& MacAulay, 2016) and empirical (Kaplan \& Orlikowski, 2012) work in this space.

Third, following our argument on the separation of value creation and capture, we call for more work to study control points and their origination, defense, application, and actual operationalization. Approaches such as design structure matrices (MacCormack, Rusnak, \& Baldwin, 2006) or qualitative comparative analysis (e.g., Ragin, 2000) applied at the level of ecosystem blueprints seem particularly promising. Our findings suggest that firms can choose for their ecosystem among configurations of interdependencies with components suppliers and complementors, and control points predicated on strong IP or unique customer access, depending on firm strategy. These choices suggest the need to revisit assumptions of ecosystem uniformity and to establish a typology of ecosystem designs best suited to varying contexts from a configuration theory perspective, as preliminarily proposed by Pagani (2013), so as to understand which type of control point is most applicable when.

Fourth, drawing on system dynamics and feedback control theory (see also Morecroft, 2007; Repenning \& Sterman, 2002), future work should elaborate in particular on the competitive dynamics in which these control points come into play, as well as considering whether further insight may be garnered by importing additional concepts, such as entropy, to explain the development of innovation ecosystems. In addition-and beyond the suggestions we have made above-this perspective may allow for extending discussions on the demand side perspective of the resource-based view (Priem et al., 2013).

Finally, our process model explains how the mutually delayed commitment of resources by both internal and external actors was bootstrapped by managers responsible for de novo ecosystem creation. This enacted resonance is a central concept of our theorizing, for which we imagine exciting avenues for further research. Assuming a typology of ecosystems, does resonance play a more central role in some types than in others? Should resonance be built at faster speed (higher frequencies) under certain conditions? These research questions also induce methodological issues around the operationalization of the "clarity" of the envisioned blueprint or the characterization of "momentum." Is there a clarity cut-off point beyond which the universe of potential futures becomes more graspable and clear assumptions can finally be formulated according to the real-options logic? Here, simulation studies could also identify the appropriate levers to reach the tipping point of momentum required to create the self-sustaining performativity of an ecosystem blueprint championed by a firm.

Potential shortcomings aside, we have presented a revised model of ecosystem creation that tries to account for the uncertainty inherent in such endeavors when they originate from generative technologies-in our cases, deep within the technological architecture. We have shown how a systems perspective emphasizing dynamic control holds the potential to extend our understanding of how ecosystems can be effectively designed in this context. In doing so, we hope that we have set the stage for a fruitful area of research that will continue to inform academe and practice alike.

\section{REFERENCES}

Adner, R. 2006. Match your innovation strategy to your innovation ecosystem. Harvard Business Review, 84: 98-107.

Adner, R. 2012. The wide lens: What successful innovators see that others miss. New York, NY: Portfolio/Penguin.

Adner, R., \& Kapoor, R. 2010. Value creation in innovation ecosystems: How the structure of technological interdependence affects firm performance in new technology generations. Strategic Management Journal, 31: 306-333.

Adner, R., \& Kapoor, R. 2016. Innovation ecosystems and the pace of substitution: Re-examining technology s-curves. Strategic Management Journal, 37: 625-648.

Adner, R., \& Levinthal, D. A. 2004. What is not a real option: Considering boundaries for the application of real options to business strategy. Academy of Management Review, 29: 74-85.

Adner, R., Oxley, J. E., \& Silverman, B. S. 2013. Introduction: Collaboration and competition in business ecosystems. Advances in Strategic Management, 30: ix-xviii.

Alexy, O., George, G., \& Salter, A. 2013. Cui bono? The selective revealing of knowledge and its implications for innovative activity. Academy of Management Review, 38: 270-291.

Alexy, O., West, J., Klapper, H., \& Reitzig, M. 2017. Surrendering control to gain advantage: Reconciling 
openness and the resource-based view of the firm. Strategic Management Journal. Published online ahead of print.

Anderson, P. 1999. Perspective: Complexity theory and organization science. Organization Science, 10: 216232.

Ansari, S. S., Garud, R., \& Kumaraswamy, A. 2015. The disruptor's dilemma: Tivo and the US television ecosystem. Strategic Management Journal, 37: 18291853.

Arend, R. J., Sarooghi, H., \& Burkemper, A. C. 2016. Effectuation, not being pragmatic or process theorizing, remains ineffectual: Responding to the commentaries. Academy of Management Review, 41: 549-556.

Autio, E., \& Thomas, L. 2013. Innovation ecosystems: Implications for innovation management. In M. Dodgson, N. Phillips \& D. M. Gann (Eds.), The Oxford handbook of innovation management: 204-228. Oxford, U.K.: Oxford University Press.

Azoulay, P., Repenning, N. P., \& Zuckerman, E. W. 2010. Nasty, brutish, and short: Embeddedness failure in the pharmaceutical industry. Administrative Science Quarterly, 55: 472-507.

Baker, T., \& Nelson, R. E. 2005. Creating something from nothing: Resource construction through entrepreneurial bricolage. Administrative Science Quarterly, 50: 329-366.

Baldwin, C. Y. 2015 ( May 27). Bottlenecks, modules and dynamic architectural capabilities. Available at https://ssrn. com/abstract $=2512209$. Accessed October 20, 2016.

Baldwin, C. Y., \& Clark, K. B. 2000. Design rules: The power of modularity. Cambridge, MA: MIT Press.

Baldwin, C. Y., \& Woodard, C. J. 2007 (December 20). Competition in modular clusters. Available at http:// www.hbs.edu/research/pdf/08-042.pdf. Accessed October 2, 2014.

Bodrožić, Z., \& Adler, P. S. 2017. The evolution of management models. Administrative Science Quarterly. Published online ahead of print.

Boudreau, K. 2010. Open platform strategies and innovation: Granting access vs. devolving control. Management Science, 56: 1849-1872.

Bresnahan, T. F., \& Greenstein, S. 1999. Technological competition and the structure of the computer industry. The Journal of Industrial Economics, 47: 1-40.

Casadesus-Masanell, R., \& Yoffie, D. B. 2007. Wintel: Cooperation and conflict. Management Science, 53: 584-598.

Ceccagnoli, M., Forman, C., Huang, P., \& Wu, D. 2012. Cocreation of value in a platform ecosystem: The case of enterprise software. Management Information Systems Quarterly, 36: 263-290.

Chesbrough, H. W. 2003. Open innovation: The new imperative for creating and profiting from technology. Boston, MA: Harvard Business School Press.

Corley, K. G., \& Gioia, D. A. 2011. Building theory about theory building: What constitutes a theoretical contribution? Academy of Management Review, 36: 12-32.

Davis, J. P. 2013. The emergence and coordination of synchrony in organizational ecosystems. Advances in Strategic Management, 30: 197-237.

Davis, J. P. 2016. The group dynamics of interorganizational relationships: Collaborating with multiple partners in innovation ecosystems. Administrative Science Quarterly, 61: 621-661.

Dhanaraj, C., \& Parkhe, A. 2006. Orchestrating innovation networks. Academy of Management Review, 31: 659669.

Dougherty, D., \& Dunne, D. D. 2011. Organizing ecologies of complex innovation. Organization Science, 22: 1214-1223.

Dunne, D. D., \& Dougherty, D. 2016. Abductive reasoning: How innovators navigate in the labyrinth of complex product innovation. Organization Studies, 37: 131159.

Eaton, B., Elaluf-Calderwood, S., Sørensen, C., \& Yoo, Y. 2011. Dynamic structures of control and generativity in digital ecosystem service innovation: The cases of the Apple and Google mobile app stores. Working Paper, 183. London School of Economics and Political Science.

Edelman, B. 2015. How to launch your digital platform. Harvard Business Review, 93: 90-97.

Edmondson, A. C., \& McManus, S. E. 2007. Methodological fit in management field research. Academy of Management Review, 32: 1155-1179.

Eisenhardt, K. M. 1989. Building theories from case study research. Academy of Management Review, 14: 532-550.

Eisenmann, T. R. 2008. Managing proprietary and shared platforms. California Management Review, 50: 31-53.

Gambardella, A., \& McGahan, A. M. 2010. Business-model innovation: General purpose technologies and their implications for industry structure. Long Range Planning, 43: 262-271.

Garnsey, E., Lorenzoni, G., \& Ferriani, S. 2008. Speciation through entrepreneurial spin-off: The Acorn-ARM story. Research Policy, 37: 210-224.

Gawer, A. 2009. Platforms, markets and innovation. Cheltenham, U.K.: Edward Elgar. 
Gawer, A. 2014. Bridging differing perspectives on technological platforms: Toward an integrative framework. Research Policy, 43: 1239-1249.

Gawer, A., \& Cusumano, M. A. 2002. Platform leadership: How Intel, Microsoft, and Cisco drive industry innovation. Cambridge, MA: Harvard Business School Press.

Gioia, D. A., Corley, K. G., \& Hamilton, A. L. 2013. Seeking qualitative rigor in inductive research: Notes on the Gioia methodology. Organizational Research Methods, 16: 15-31.

Gruber, M., MacMillan, I. C., \& Thompson, J. D. 2008. Look before you leap: Market opportunity identification in emerging technology firms. Management Science, 54: 1652-1665.

Gruber, M., MacMillan, I. C., \& Thompson, J. D. 2013. Escaping the prior knowledge corridor: What shapes the number and variety of market opportunities identified before market entry of technology start-ups? Organization Science, 24: 280-300.

Hannah, D. P., \& Eisenhardt, K. M. 2015. Origins and outcomes of strategy in nascent ecosystems, Academy of Management Proceedings. Available at: http:// proceedings.aom.org/content/2015/1/13330.

Iansiti, M., \& Levien, R. 2004. The keystone advantage: What the new dynamics of business ecosystems mean for strategy, innovation, and sustainability. Boston, MA: Harvard Business School Press.

Ingraham, N. 2013 (April 26, 2013). iTunes store at 10: How Apple built a digital media juggernaut. Available at http://www.theverge.com/2013/4/26/4265172/itunesstore-at-10-how-apple-built-a-digital-media-juggernaut.

Jacobides, M. G., Knudsen, T., \& Augier, M. 2006. Benefiting from innovation: Value creation, value appropriation and the role of industry architectures. Research Policy, 35: 1200-1221.

Jacobides, M. G., MacDuffie, J. P., \& Tae, C. J. 2016. Agency, structure, and the dominance of OEMs: Change and stability in the automotive sector. Strategic Management Journal, 37: 1942-1967.

Jacobides, M. G., \& Tae, C. J. 2015. Kingpins, bottlenecks, and value dynamics along a sector. Organization Science, 26: 889-907.

Jain, S. 2012. Pragmatic agency in technology standards setting: The case of ethernet. Research Policy, 41: 1643-1654.

Jick, T. D. 1979. Mixing qualitative and quantitative methods: Triangulation in action. Administrative Science Quarterly, 24: 602-611.

Kaplan, S., \& Orlikowski, W. J. 2012. Temporal work in strategy making. Organization Science, 24: 965-995.
Kapoor, R., \& Furr, N. R. 2015. Complementarities and competition: Unpacking the drivers of entrants' technology choices in the solar photovoltaic industry. Strategic Management Journal, 36: 416-436.

Kapoor, R., \& Lee, J. M. 2013. Coordinating and competing in ecosystems: How organizational forms shape new technology investments. Strategic Management Journal, 34: 274-296.

Kim, W. C., \& Mauborgne, R. 2005. Blue ocean strategy: How to create uncontested market space and make the competition irrelevant. Boston, MA: Harvard Business School Publishing.

Knudsen, T., \& Levinthal, D. A. 2007. Two faces of search: Alternative generation and alternative evaluation. Organization Science, 18: 39-54.

Langley, A. 1999. Strategies for theorizing from process data. Academy of Management Review, 24: 691-710.

Le Masson, P., Weil, B., \& Hatchuel, A. 2009. Platforms for the design of platforms: Collaborating in the unknown. In A. Gawer (Ed.), Platforms, markets and innovation: 273-305. Cheltenham, U.K.: Edward Elgar.

Leonard-Barton, D. 1990. A dual methodology for case studies: Synergistic use of a longitudinal single site with replicated multiple sites. Organization Science, 1: 248-266.

Lieberman, M. B., \& Montgomery, D. B. 1998. First-mover (dis)advantages: Retrospective and link with the resource-based view. Strategic Management Journal, 19: 1111-1125.

Locke, K., Golden-Biddle, K., \& Feldman, M. S. 2008. Perspective-making doubt generative: Rethinking the role of doubt in the research process. Organization Science, 19: 907-918.

Lord, R. G., Dinh, J. E., \& Hoffman, E. L. 2015. A quantum approach to time and organizational change. Academy of Management Review, 40: 263-290.

Lusch, R. F., \& Nambisan, S. 2015. Service innovation: A service-dominant logic perspective. Management Information Systems Quarterly, 39: 155-175.

MacCormack, A. D., Rusnak, J., \& Baldwin, C. Y. 2006. Exploring the structure of complex software designs: An empirical study of open source and proprietary code. Management Science, 52: 1015-1030.

Mantere, S., \& Ketokivi, M. 2013. Reasoning in organization science. Academy of Management Review, 38: 70-89.

McGrath, R. G. 2013. The end of competitive advantage: How to keep your strategy moving as fast as your business. Boston, MA: Harvard Business Review Press.

McGrath, R. G., \& MacMillan, I. C. 2000. The entrepreneurial mindset: Strategies for continuously 
creating opportunity in an age of uncertainty. Boston, MA: Harvard Business Press.

McGrath, R. G., \& MacMillan, I. C. 2009. Discovery-driven growth: A breakthrough process to reduce risk and seize opportunity. Boston, MA: Harvard Business Press.

McIntyre, D. P., \& Subramaniam, M. 2009. Strategy in network industries: A review and research agenda. Journal of Management, 35: 1494-1517.

Möller, K. 2010. Sense-making and agenda construction in emerging business networks-How to direct radical innovation. Industrial Marketing Management, 39: 361-371.

Moore, J. F. 1996. The death of competition: Leadership and strategy in the age of business ecosystems. New York, NY: HarperBusiness.

Morecroft, J. D. W. 2007. Strategic modelling and business dynamics: A feedback systems approach. Chichester, U.K.: John Wiley \& Sons.

Nambisan, S., \& Baron, R. A. 2013. Entrepreneurship in innovation ecosystems: Entrepreneurs' self-regulatory processes and their implications for new venture success. Entrepreneurship Theory and Practice, 37: 1071-1097.

Nambisan, S., \& Sawhney, M. 2011. Orchestration processes in network-centric innovation: Evidence from the field. The Academy of Management Perspectives, 25: 40-57.

Narayanan, V. K., \& Chen, T. 2012. Research on technology standards: Accomplishment and challenges. Research Policy, 41: 1375-1406.

Nonaka, I., \& Takeuchi, H. 2011. The wise leader. Harvard Business Review, 89: 58-67.

Osterwalder, A., \& Pigneur, Y. 2010. Business model generation: A handbook for visionaries, game changers, and challengers. Hoboken, NJ: John Wiley \& Sons.

Ozcan, P., \& Eisenhardt, K. M. 2009. Origin of alliance portfolios: Entrepreneurs, network strategies, and firm performance. Academy of Management Journal, 52: 246-279.

Ozcan, P., \& Santos, F. M. 2015. The market that never was: Turf wars and failed alliances in mobile payments. Strategic Management Journal, 36: 1486-1512.

Pagani, M. 2013. Digital business strategy and value creation: Framing the dynamic cycle of control points. Management Information Systems Quarterly, 37: 617-632.

Peirce, C. S. 1878. Deduction, induction, and hypothesis. Popular Science Monthly, 13: 470-482.

Polidoro, F., \& Toh, P. K. 2011. Letting rivals come close or warding them off? The effects of substitution threat on imitation deterrence. Academy of Management Journal, 54: 369-392.

Priem, R. L. 2007. A consumer perspective on value creation. Academy of Management Review, 32: 219-235.

Priem, R. L., Butler, J. E., \& Li, S. 2013. Toward reimagining strategy research: Retrospection and prospection on the 2011 AMR decade award article. Academy of Management Review, 38: 471-489.

Ragin, C. C. 2000. Fuzzy-set social science. Chicago, IL: The University of Chicago Press.

Reetz, D. K., \& MacAulay, S. 2016. Beyond ill-structured problems: Tackling true novelty through co-evolutionary search. 36th Strategic Management Conference SMS, Berlin.

Repenning, N. P., \& Sterman, J. D. 2002. Capability traps and self-confirming attribution errors in the dynamics of process improvement. Administrative Science Quarterly, 47: 265-295.

Ries, E. 2011. The lean startup: How today's entrepreneurs use continuous innovation to create radically successful businesses. New York, NY: Crown Business.

Santos, F., \& Eisenhardt, K. 2009. Constructing markets and shaping boundaries: Entrepreneurial power in nascent fields. Academy of Management Journal, 52 : 643-671.

Sarasvathy, S. D. 2001. Causation and effectuation: Toward a theoretical shift from economic inevitability to entrepreneurial contingency. Academy of Management Review, 26: 243-263.

Sarasvathy, S. D., Dew, N., Read, S., \& Wiltbank, R. 2008. Designing organizations that design environments: Lessons from entrepreneurial expertise. Organization Studies, 29: 331-350.

Schmidt, J., \& Keil, T. 2013. What makes a resource valuable? Identifying the drivers of firm-idiosyncratic resource value. Academy of Management Review, 38: 206-228.

Soh, P.-H. 2010. Network patterns and competitive advantage before the emergence of a dominant design. Strategic Management Journal, 31: 438-461.

Sterman, J. D. 2000. Business dynamics: Systems thinking and modeling for a complex world. New York, NY: McGraw-Hill.

Stieglitz, N., Knudsen, T., \& Becker, M. C. 2016. Adaptation and inertia in dynamic environments. Strategic Management Journal, 37: 1854-1864.

Strauss, A., \& Corbin, J. 1998. Basics of qualitative research: Techniques and procedures for developing grounded theory (2nd ed.). Thousand Oaks, CA: Sage.

Suarez, F., \& Lanzolla, G. 2005. The half-truth of first-mover advantage. Harvard Business Review, 83: 121-127. 
Suarez, F. F., \& Utterback, J. M. 1995. Dominant designs and the survival of firms. Strategic Management Journal, 16: 415-430.

Sull, D. N. 2005. Strategy as active waiting. Harvard Business Review, 83: 120-129.

Sull, D. N. 2007. Closing the gap between strategy and execution. MIT Sloan Management Review, 48: 3038.

Teece, D. J. 1986. Profiting from technological innovation: Implications for integration, collaboration, licensing and public policy. Research Policy, 15: 285-305.

Thomas, L., Autio, E., \& Gann, D. 2014. Architectural leverage: Putting platforms in context. The Academy of Management Perspectives, 28: 198-219.

Tilson, D., Lyytinen, K., \& Sørensen, C. 2010. Research commentary-digital infrastructures: The missing IS research agenda. Information Systems Research, 21: 748-759.

Tsang, E. W. K., \& Williams, J. N. 2012. Generalization and induction: Misconceptions, clarifications, and a classification of induction. Management Information Systems Quarterly, 36: 729-748.

Tsang, E. W. K. 2013. Case study methodology: Causal explanation, contextualization, and theorizing. Journal of International Management, 19: 195-202.

Van de Ven, A. H. 2007. Engaged scholarship: A guide for organizational and social research: $A$ guide for organizational and social research. Oxford, U.K.: Oxford University Press.

van der Borgh, M., Cloodt, M., \& Romme, A. G. L. 2012. Value creation by knowledge-based ecosystems: Evidence from a field study. $\boldsymbol{R} \boldsymbol{\&} \boldsymbol{D}$ Management, 42: 150-169.

Wareham, J., Fox, P. B., \& Cano Giner, J. L. 2014. Technology ecosystem governance. Organization Science, 25: 1195-1215.
Williamson, P. J., \& De Meyer, A. 2012. Ecosystem advantage: How to successfully harness the power of partners. California Management Review, 55: 24-46.

Yin, R. K. 2014. Case study research: Design and methods (5th ed.). Thousand Oaks, CA: SAGE.

Yoo, Y., Henfridsson, O., \& Lyytinen, K. 2010. Research commentary-the new organizing logic of digital innovation: An agenda for information systems research. Information Systems Research, 21: 724-735.

Zittrain, J. L. 2006. The generative internet. Harvard Law Review, 119: 1974-2040.

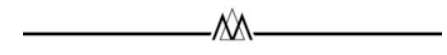

Brice Dattée (dattee@em-lyon.com) is associate professor of strategic management at Emlyon Business School in France. He received his $\mathrm{PhD}$ in management science jointly from Ecole Centrale Paris, France, and University College Dublin, Ireland. He is currently a visiting associate professor at London Business School. His research focuses on social dynamics and competitive strategy in technology-based industries.

Oliver Alexy (o.alexy@tum.de) is professor of strategic entrepreneurship at TUM School of Management, Technische Universität München, where he was also awarded his $\mathrm{PhD}$. His current research focuses on effective organization designs for high-uncertainty environments.

Erkko Autio (erkko.autio@imperial.ac.uk) is chair of entrepreneurship and technology transfer at Imperial College Business School, London. He is also a part-time professor at Tilburg University School of Economies and Management. His research focuses on entrepreneurial ecosystems, innovation ecosystems, comparative entrepreneurship, digitalization, and international entrepreneurship. He received his $\mathrm{PhD}$ from Helsinki University of Technology. 
APPENDIX A

TABLE A1

Dynamic Control of Ecosystem Feedback Loops

R1

\begin{tabular}{|c|c|c|c|}
\hline \multirow[t]{3}{*}{ Name } & \multirow[t]{3}{*}{ NARROWING THE FUTURE } & \multirow[t]{3}{*}{ Influencing } & Select first applications \\
\hline & & & Develop technology \\
\hline & & & Engage with selected customers \\
\hline Goal & Establish protovision & Monitoring & Scan technological convergence \\
\hline \multirow[t]{3}{*}{ Description } & \multirow{3}{*}{$\begin{array}{l}\text { Developments in a deep-layer technology lead to } \\
\text { a narrower range of applications. } \\
\text { Heterogeneous applications require further } \\
\text { technological developments. }\end{array}$} & \multirow[t]{3}{*}{ Updating } & Understand use cases \\
\hline & & & Test design assumptions \\
\hline & & & Update protovision \\
\hline \multicolumn{4}{|l|}{ R2 } \\
\hline Name & KEEPING UP & Influencing & $\begin{array}{l}\text { Editorial decisions over the roadmap. Develop } \\
\text { technology. Vetting. }\end{array}$ \\
\hline Goal & Provide the necessary enablers & Monitoring & Requests for specification changes. \\
\hline Description & $\begin{array}{l}\text { Initial switch to an ecosystem model is triggered by an } \\
\text { external pull. Resource commitment inscribes } \\
\text { a certain, albeit unpredictable, direction to the } \\
\text { ecosystem dynamics. Focal firm must keep up. }\end{array}$ & Updating & Update roadmap to fit requests \\
\hline Name & ROADMAPPING AND PREEMPTING & Influencing & $\begin{array}{l}\text { Develop future resources } \\
\text { Build business case } \\
\text { Define tech roadmap }\end{array}$ \\
\hline Goal & Establish future control points & Monitoring & $\begin{array}{l}\text { Notice emergence of novel applications. Monitor } \\
\text { changes in strategy. }\end{array}$ \\
\hline Description & $\begin{array}{l}\text { Focal firm infers future control points and roadmaps } \\
\text { development efforts to increasingly confine the } \\
\text { ecosystem dynamics on a favorable path. }\end{array}$ & Updating & $\begin{array}{l}\text { Modify business case } \\
\text { Update roadmap }\end{array}$ \\
\hline
\end{tabular}

R4

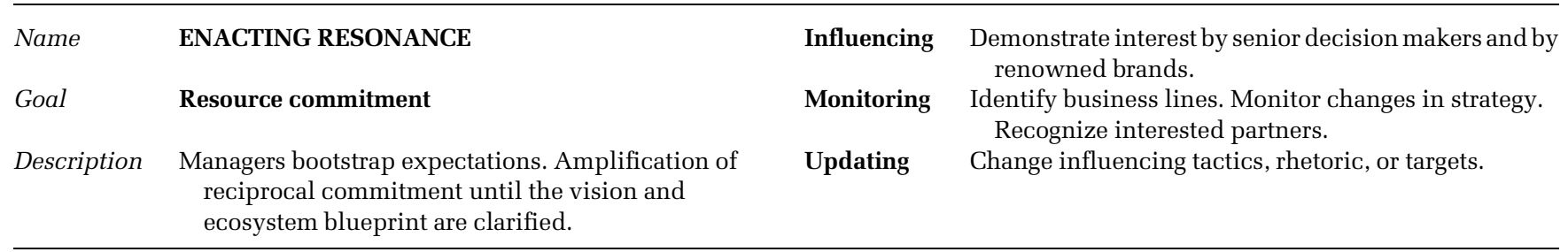

B1

\begin{tabular}{llll}
\hline $\begin{array}{l}\text { Name } \\
\text { Goal }\end{array}$ & $\begin{array}{l}\text { ECOSYSTEM DRIFTING } \\
\text { Counteract to preserve blueprint }\end{array}$ & $\begin{array}{l}\text { Influencing } \\
\text { Monitoring }\end{array}$ & $\begin{array}{l}\text { Convince others of the opportunities in your blueprint } \\
\text { Keep track of ecosystem momentum } \\
\text { Notice emergence of novel applications }\end{array}$ \\
& $\begin{array}{l}\text { The maneuvering and creative agency of an } \\
\text { increasingly large number of external players has } \\
\text { the potential to dissolve the emerging blueprint. }\end{array}$ & Updating & $\begin{array}{l}\text { Update the value blueprint with emerging } \\
\text { interdependencies }\end{array}$
\end{tabular}

B2

Name

SLIDING POSITIONS

Goal

Continuous adjustment of business case

Description Build momentum around control points in the envisioned blueprint. Maintain a central position. Counteract sliding by adjusting business case.
Influencing Imprint vision on others. Claim centrality. Shape direction and rate of their roadmaps. Vet.

Monitoring Emergence of novel application. Estimate others' centrality.

Updating Change business case to suit powerful others or to preempt others. 